\title{
SAFETY ASSESSMENT OF EUROCODE 3 STABILITY DESIGN RULES FOR THE LATERAL-TORSIONAL BUCKLING OF PRISMATIC BEAMS
}

\author{
Luís Simões da Silva ${ }^{1}$, Trayana Tankova ${ }^{1, *}$, Liliana Marques $^{1}$, Carlos Rebelo $^{1}$ and Andreas Taras ${ }^{2}$ \\ ${ }^{I}$ ISISE, Department of Civil Engineering, University of Coimbra, Coimbra, Portugal \\ ${ }^{2}$ Institute of Structural Engineering, Bundeswehr University Munich, Germany \\ *(Corresponding author: Email: ttankova@uc.pt)
}

Received: 17 June 2017; Revised: 26 December 2017; Accepted: 27 December 2017

\begin{abstract}
This paper presents the safety assessment of the European rules for the lateral-torsional buckling of beams using hot-rolled I and $\mathrm{H}$ cross-sections based on a large number of advanced numerical simulations covering the relevant parameters.

The methods for LTB in Eurocode 3 are briefly presented and assessed. Despite the large scatter of results, the conservative nature of the "General Case" design rule was confirmed. The "Special Case" systematically led to significantly lower safety levels. A new Ayrton-Perry-based method was also assessed and it was shown to provide good accuracy.

The magnitude of the partial factor $\gamma_{\mathrm{M} 1}{ }^{*}$ is addressed, whereby a good homogeneity of results is observed across the different buckling curves, with maximum variations of 0.05 , except for the "Special Case", which systematically presents higher factors for most of the subsets. The "General Case" presents the lowest partial factors, but is clearly over conservative, leading in many cases up to $40 \%$ lower resistance.

The $\gamma_{\mathrm{M} 1} *$ values are compared for the "General Case" and the new Ayrton-Perry method with the results obtained for the flexural buckling resistance of columns. It is concluded that the partial factors for LTB are generally lower than those for flexural buckling.
\end{abstract}

Keywords: Beam, lateral-torsional buckling, safety assessment, design rules, steel, Eurocode 3, stability

DOI: $10.18057 /$ IJASC.2018.14.9

\section{INTRODUCTION}

The design verification of beams susceptible to lateral-torsional instability in Eurocode 3 [1] is based on the buckling curve approach. The code proposes two methods for the lateral-torsional buckling verification - the "General" and the "Special" cases. The safety and accuracy of these methods was addressed in the past, e.g. by Snijder and Hoenderkamp [4] and Rebelo et al [5], where discrepancies between numerical simulations and the code predictions were identified. Recently, a new design method based on a mechanically sound analytical derivation was proposed by Taras [3] that strictly implements an Ayrton-Perry approach akin to the derivation of the flexural buckling resistance of columns [6].

There are various parameters which influence the stability behaviour of beams: material properties, geometrical dimensions, imperfections. Some of these parameters are constantly monitored as part of the quality control production procedures, while others are occasionally measured, such as residual stresses and initial imperfections, making it more difficult to choose representative values to be used in numerical simulations. Moreover, the development of new structural steels with largely improved mechanical and geometrical properties and improved quality control procedures further supports the need for a reassessment of the safety levels of the European design rules for lateral-torsional buckling. 
Hence, based on the findings of the RFCS SAFEBRICTILE project [9] and similarly to a previous paper on columns [10], this paper addresses a systematic assessment of the safety levels of the lateral-torsional buckling of I-shaped hot-rolled steel beams according to Eurocode 3 [1]. Firstly, the adopted assumptions for the assessment are summarized. A parametric study for the evaluation of lateral-torsional buckling design rules for prismatic beams in EUROCODE 3 [1] is subsequently carried out. It covers several slenderness groups, yield stress, cross-section shapes, and bending moment distributions such that a thorough evaluation of the analyzed design rules is achieved, using advanced nonlinear numerical simulations. Finally, a discussion on the value of the partial factor $\gamma_{M} 1^{*}$ to be adopted based on the obtained results is presented.

\section{DESIGN APPROACHES FOR THE LATERAL-TORSIONAL BUCKLING OF PRISMATIC HOT-ROLLED BEAMS}

According to Eurocode 3 [1], the design resistance of beams prone to lateral-torsional buckling can be estimated using clauses 6.3.2.2 and 6.3.2.3, the so-called General Case and Special Case, respectively. Both of them make use of the buckling curve approach, thus assuming that the columns and beams have similar behaviour regarding their buckling resistance.

The General Case (see Table 1) uses the column buckling curves; however, the split between the various cases is done only according to the section depth-to-width $(\mathrm{h} / \mathrm{b})$ ratios, since beams with lower $\mathrm{h} / \mathrm{b}$ have higher torsional rigidity and thus higher lateral-torsional buckling resistance. The method has been criticised for being overly conservative for variable bending moment distributions and for the large scatter of results [3], [5].

As an alternative for $\mathrm{H}$ and I sections, the Special Case (see Table 1) considers the beneficial effect of the torsional resistance of the member and accounts for the favourable effect of varying bending moment distributions along the beam length by modifying the reduction factor $\chi_{\mathrm{LT}}$ with a factor $\mathrm{f}$ (see Table 3). The Special Case also makes use of a longer plateau length by recommending $\bar{\lambda}_{L T, 0}=0.4$. However, its estimation of the design resistance is often found to be unconservative when compared to numerical simulations. [3], [5]. As a result, in [5] a modification of the General case was proposed, referred to as General Case/f, whereby the reduction factor $\chi_{\mathrm{LT}}$ calculated using the General Case's curves is modified by the factor $\mathrm{f}$ provided for the Special Case.

Recent research by Taras [3] has resulted in a new Ayrton-Perry design rule (see Table 1), which is based on a mechanically consistent analytical derivation and imperfection factors (Table 2) calibrated based on an extensive numerical parametric study. The method was also statistically assessed using available experimental test results and Monte Carlo simulations. It is henceforth referred to as New EC3 method or nEC3.

All methods rely on a reference case (simply-supported beam with fork conditions at the supports and uniform bending moment). The application to different loading types or boundary conditions is addressed by calculating the appropriate elastic critical moment and a specific coefficient to correct the second-order critical location. It is noted that for cases with restrained warping conditions at the supports this approach leads to slightly unsafe sided results, when compared to the correct derivation of the design resistance.

The design procedures are summarized in Table 1, whereas the imperfection factors and additional factors are summarized in Table 2 and Table 3 respectively. 
Table 1. Lateral-torsional Buckling Resistance of Beams

\begin{tabular}{|c|c|c|c|c|}
\hline Method & $\begin{array}{l}\text { EC } 3 \text { GC } \\
\text { (clause } \\
\text { 6.3.2.2) }\end{array}$ & $\begin{array}{c}\text { EC } 3 \\
\text { GC/f } \\
\text { (GC mod. } \\
\text { with } \boldsymbol{f} \\
\text { factor [5] }\end{array}$ & $\begin{array}{c}\text { EC 3, SC } \\
\text { (clause 6.3.2.3) }\end{array}$ & New EC3 method \\
\hline$M_{y, R k}$ & \multicolumn{4}{|c|}{$\begin{array}{c}W_{p l, y} \cdot f_{y}-\text { class } 1 \text { or } 2 \text { cross sections } \\
W_{e l, y} \cdot f_{y}-\text { class } 3 \text { cross sections } \\
W_{e f f, y} \cdot f_{y} \text { - class } 4 \text { cross sections }\end{array}$} \\
\hline$M_{c r}$ & \multicolumn{4}{|c|}{ Elastic critical moment (LBA) } \\
\hline $\bar{\lambda}_{L T}$ & \multicolumn{4}{|c|}{$\bar{\lambda}_{L T}=\sqrt{M_{y, R k} / M_{C R}}$} \\
\hline$\alpha_{L T}$ & \multicolumn{4}{|c|}{ See Table 2} \\
\hline$\eta_{L T}$ & \multicolumn{2}{|c|}{$\alpha_{L T}\left(\bar{\lambda}_{L T}-0.2\right)$} & $\begin{array}{c}\alpha_{L T}\left(\bar{\lambda}_{L T}-\bar{\lambda}_{L T, 0}\right) \\
\bar{\lambda}_{L T, 0}=0.4 \\
\text { (recommended) }\end{array}$ & $\alpha_{L T}\left(\bar{\lambda}_{z}-0.2\right)$ \\
\hline
\end{tabular}

Table 1. (continued) Lateral-torsional buckling resistance of beams.

\begin{tabular}{|c|c|c|c|c|}
\hline Method & $\begin{array}{l}\text { EC } 3 \text { GC } \\
\text { (clause } \\
\text { 6.3.2.2) }\end{array}$ & $\begin{array}{c}\text { EC 3 } \\
\text { GC/f } \\
(G C \\
\text { mod. } \\
\text { with } f \\
\text { factor }[5] \\
\end{array}$ & $\begin{array}{c}\text { EC 3, SC } \\
\text { (clause 6.3.2.3) }\end{array}$ & New EC3 method \\
\hline$\eta_{L T}$ & \multicolumn{2}{|c|}{$\alpha_{L T}\left(\bar{\lambda}_{L T}-0.2\right)$} & $\begin{array}{c}\alpha_{L T}\left(\bar{\lambda}_{L T}-\bar{\lambda}_{L T, 0}\right) \\
\bar{\lambda}_{L T, 0}=0.4 \\
\text { (recommended) }\end{array}$ & $\alpha_{L T}\left(\bar{\lambda}_{z}-0.2\right)$ \\
\hline$\Phi_{L T}$ & \multicolumn{2}{|c|}{$0.5 \times\left(1+\eta_{L T}+\bar{\lambda}_{L T}^{2}\right)$} & $\begin{array}{c}0.5 \times\left(1+\eta_{L T}+\beta \bar{\lambda}_{L T}^{2}\right) \\
\beta=0.75 \\
\text { (recommended) }\end{array}$ & $\begin{array}{c}0.5 \times\left(1+f_{M}\left(\eta_{L T} \frac{\bar{\lambda}_{L T}^{2}}{\bar{\lambda}_{z}^{2}}+\bar{\lambda}_{L T}{ }^{2}\right)\right) \\
\left(\text { Table } 3 \text { for } f_{M}\right)\end{array}$ \\
\hline$\chi_{L T}$ & \multicolumn{2}{|l|}{$\phi_{L T}+\sqrt{\phi}$} & $\begin{array}{l}\frac{1}{\phi_{L T}+\sqrt{\phi_{L T}{ }^{2}-\beta \bar{\lambda}_{L T}{ }^{2}}} \\
\leq\left\{\begin{array}{l}1 \\
\frac{1}{\bar{\lambda}_{L T}{ }^{2}}\end{array}\right.\end{array}$ & $\frac{f_{M}}{\phi_{L T}+\sqrt{\phi_{L T}^{2}-f_{M} \bar{\lambda}_{L T}^{2}}} \leq 1$ \\
\hline$\left(\chi_{L T, m o d}\right)$ & - & $\begin{array}{l}\frac{\chi_{L T}}{f} \leq 1 \\
\text { (Table } 3 \\
\text { for } f \text { ) }\end{array}$ & $\frac{\chi_{L T}}{f} \leq 1$ & - \\
\hline Verification & \multicolumn{4}{|c|}{$M_{y, E d} \leq M_{b, R d}=\chi_{L T(\text { mod })} \times M_{y, R k} / \gamma_{M 1}$} \\
\hline
\end{tabular}

$f_{M}, k_{c}$ and $f$ are additional factors respectively for $\mathrm{nEC} 3$ and SC, see Table 3. 
Additionally, whenever $\bar{\lambda}_{L T} \leq \bar{\lambda}_{L T, 0}$ and $\frac{M_{y, E d}}{M_{c r}} \leq \bar{\lambda}_{L T, 0}{ }^{2}$, lateral torsional buckling does not need to be verified and only cross-sectional checks apply $\left(\chi_{L T}=1\right)$.

In order to provide a more thorough overview, the 2010 AISC [11] design rules for the lateral-torsional buckling resistance of doubly symmetric I-shaped members and channels bent about their major axis are also briefly presented in Table 4.

The AISC lateral-torsional buckling verification considers three slenderness regions that depend on the length $\mathrm{L}_{b}$ between points that are either braced against lateral displacement of the compression flange or braced against twist of the cross section. All symbols are explained in the notation.

Table 2. Imperfection Factors and Generalized Imperfection Limits for Lateral-torsional Buckling

\begin{tabular}{|c|c|c|c|c|c|c|}
\hline \multirow[b]{2}{*}{ Fabrication } & \multicolumn{3}{|c|}{ Limits } & \multicolumn{3}{|c|}{ Source and Imperfection factor } \\
\hline & & [3] & $\begin{array}{c}\text { EUROCODE } \\
3\end{array}$ & $\begin{array}{c}\text { EUROCODE } \\
3 \text { GC; GC/f }\end{array}$ & $\begin{array}{c}\text { EUROCODE } \\
3 \text { SC }\end{array}$ & New EC3 method \\
\hline \multirow{3}{*}{ Rolled } & \multirow{2}{*}{$\stackrel{\hat{\lambda}}{\hat{N}}$} & $\mathrm{t}_{\mathbf{1}} \leq \mathbf{4 0 \mathrm { mm }}$ & $\begin{array}{l}\mathbf{h} / \mathbf{b}>\mathbf{2 . 0} \\
\mathbf{h} / \mathbf{b} \leq \mathbf{2 . 0}\end{array}$ & 0.340 .21 & 0.490 .34 & $0.12 \sqrt{\frac{W_{y, e l}}{W_{z, e l}}} \leq 0.34$ \\
\hline & & $40 \mathrm{~mm}<\mathrm{t}_{\mathrm{t}} \leq 100 \mathrm{~mm}$ & $\begin{array}{l}\mathbf{h} / \mathbf{b}>\mathbf{2 . 0} \\
\mathbf{h} / \mathbf{b} \leq \mathbf{2 . 0}\end{array}$ & 0.340 .21 & 0.490 .34 & $0.16 \sqrt{\frac{W_{y, e l}}{W_{z, e l}}} \leq 0.49^{*}$ \\
\hline & 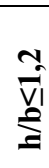 & $\mathrm{t}_{\mathrm{f}} \leq 100 \mathrm{~mm}$ & $\mathbf{h} / \mathbf{b} \leq \mathbf{2 . 0}$ & 0.21 & 0.34 & $0.16 \sqrt{\frac{W_{y, e l}}{W_{z, e l}}} \leq 0.49$ \\
\hline
\end{tabular}

Table 3. Additional Auxiliary Factors for GC/f; SC; nEC3

\begin{tabular}{|c|c|c|c|}
\hline Method & & GC/f; SC & nEC3 \\
\hline $\begin{array}{l}\text { Loading/ } \\
\text { Factor }\end{array}$ & $\mathbf{k}_{\mathbf{c}}$ & f & $\mathbf{f}_{\mathbf{M}}$ \\
\hline & $\frac{1}{1.33-0.33 \psi}=1$ & $1-0.5\left(1-k_{c}\right) \times\left[1-2\left(\bar{\lambda}_{L T}-0.8\right)^{2}\right]=1$ & $1.25-0.1 \psi-0.15 \psi^{2}=1$ \\
\hline$\Gamma$ & $\frac{1}{1.33-0.33 \psi}=0.75$ & \multirow{4}{*}{ Function of the slenderness } & $1.25-0.1 \psi-0.15 \psi^{2}=1.25$ \\
\hline$\longrightarrow$ & 0.94 & & 1.05 \\
\hline & $\frac{1}{1.33-0.33 \psi}=0.60$ & & $1.25-0.1 \psi-0.15 \psi^{2}=1.2$ \\
\hline$\Longrightarrow$ & 0.86 & & 1.11 \\
\hline
\end{tabular}


Table 4. Lateral-torsional Buckling Resistance of Beams according to AISC

\begin{tabular}{|l|l|c|c|}
\hline & $L_{b} \leq L_{p}$ & $L_{p}<L_{b} \leq L_{r}$ & $\mathrm{~L}_{\mathrm{b}}>\mathrm{L}_{\mathrm{r}}$ \\
\hline \hline$M_{n}$ & $F_{y} Z_{x}=M_{p}$ & $C_{b}\left[M_{p}-\left(M_{p}-0.7 F_{y} S_{x}\right)\left(\frac{L_{b}-L_{p}}{L_{r}-L_{p}}\right)\right] \leq M_{p}$ & $F_{c r} S_{x} \leq M_{p}$ \\
\hline$L_{p}=1.76 r_{y} \sqrt{\frac{E}{F_{y}}}$ & \\
$L_{r}=1.95 r_{t s} \frac{E}{0.7 F_{y}} \sqrt{\frac{J_{c}}{S_{x} h_{0}}+\sqrt{\left(\frac{J_{c}}{S_{x} h_{0}}\right)^{2}+6.76\left(\frac{0.7 F_{y}}{E}\right)^{2}}}$
\end{tabular}

It is noted that both the Special Case and the AISC rule [11] present an extended plateau region of the buckling curve that leads to unsafe results, as reported in [5], [12] and [13] that suggest that a shorter plateau length should be adopted.

\section{SAFETY ASSESSMENT METHODOLOGY}

\subsection{Scope and Assumptions}

In order to give a complete overview of the stability design of beams according to Eurocode 3 [1], the study covers the design rules summarized in Table 1. For each method, a wide range of I-shaped cross-sections is analyzed covering different $h / b$ ratios and flange thicknesses across various slenderness ranges. In addition, as the bending moment distribution has a considerable influence on the lateral-torsional buckling resistance, five different bending moment distributions are included in the parametric study, detailed in section 0.

The lateral-torsional resistance of the beams is obtained using advanced numerical finite element simulations. The adopted numerical model is summarized in section 0 .

In the safety assessment of the design rules carried out in section 0 , the following assumptions are considered:

- The variability of the input variables in the design model is not considered for the calibration of $\mathrm{V}_{\delta}$; the value is obtained from nominal properties since the "experimental" results are considered with nominal properties;

- The coefficient of variation of the basic variables, $V_{r t}$, considers only the variability of cross section dimensions, yield stress and modulus of elasticity; for these parameters, more information is known and documented with recent data. The adopted distributions are discussed in section 0 .

\subsection{Basis of Design}

The basis for the statistical assessment of the steel members was presented and discussed in [8]. The procedure proposed in Annex D of EN 1990 [2] is summarized in Figure 1: 


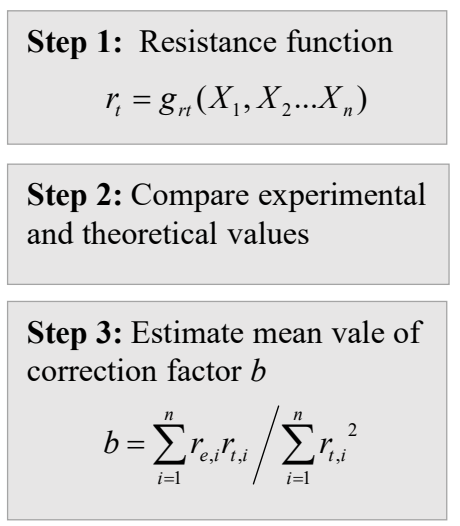

Step 4: Estimate CoV of the error:

$$
\begin{gathered}
\delta_{i}=r_{e, i} / b r_{t, i} \quad \Delta_{\mathrm{i}}=\ln \left(\delta_{\mathrm{i}}\right) \\
s_{\Delta}^{2}=\frac{1}{n-1} \sum_{i=1}^{n}\left(\Delta_{i}-\bar{\Delta}\right)^{2} \\
V_{\delta}=\sqrt{\exp \left(s_{\Delta}^{2}\right)-1}
\end{gathered}
$$

Step 5: Analyze compatibility - if the resistance function is acceptable
Step 6: Determine c.o.v $V_{r t, i}$ of the basic variables

Step 7: Determine design value of the resistance

$$
\begin{gathered}
Q_{\delta}=\sqrt{\ln \left(V_{\delta}^{2}+1\right)} \quad Q_{r t}=\sqrt{\ln \left(V_{r t}^{2}+1\right)} \\
Q=\sqrt{\ln \left(V_{\delta}^{2}+V_{r t}^{2}+1\right)} \\
r_{d}=\left[\begin{array}{ll}
b g_{r t} \underline{\left(X_{m}\right)} \exp \left(-k_{d, \infty} \frac{Q_{r t}{ }^{2}}{Q}-k_{d, n} \frac{Q_{\delta}^{2}}{Q}-0.5 Q^{2}\right) & n \leq 30 \\
b g_{r t}\left(\underline{X_{m}}\right) \exp \left(-k_{d, \infty} Q-0.5 Q^{2}\right) & n \rightarrow \infty
\end{array}\right.
\end{gathered}
$$

Figure 1. Flow Chart - Annex D

In Step 6 of the procedure given in Figure 1, $V_{r t}$ is determined as follows:

$$
V_{r t}^{2}=\frac{1}{g_{r t} \underline{\left(X_{m}\right)^{2}}} \sum_{j=1}^{k}\left(\frac{\partial g_{r t}\left(X_{j}\right)}{\partial X_{j}} \sigma_{j}\right)^{2}
$$

The partial derivatives are computed numerically using expression (2) and very small values of " $\Delta X_{\mathrm{i}}$ " for each test specimen separately, leading to a scatter of $\gamma_{\mathrm{M}, \mathrm{i}}{ }^{*}$ for each specimen.

$$
\frac{\partial r_{t}}{\partial X_{i}} \approx \frac{r_{t}\left(X_{1}, \ldots, X_{i}+\Delta X_{i}, \ldots X_{j}\right)-r_{t}\left(X_{1}, \ldots, X_{i}, \ldots X_{j}\right)}{\Delta X_{i}}
$$

\subsection{Adopted Distributions}

In order to apply the assessment procedure, pre-information regarding the statistical distributions of all basic input parameters which are used in the design calculation is necessary in step 6 of the procedure summarized in Figure 1.

In this evaluation, the variability of the material and geometrical properties are considered. The presence of imperfections is accounted using representative values of those parameters.

The recommended distributions from the European project SAFEBRICTILE [9] were used in this paper that reflect current European steel production. The statistical parameters summarized in Table 5 were considered as the reference for the variability of the yield stress. The statistical properties in Table 5 refer to the thickness range $\mathrm{t}_{\mathrm{f}}<16 \mathrm{~mm}$. For higher flange thicknesses, the corresponding mean value should be obtained by multiplying the nominal value according to EN 10025 [14] with the ratio $f_{y m} / f_{y, n o m}$ and the coefficient of variation should be kept constant. These distributions were considered for the computation of the $\gamma_{\mathrm{Mi}}{ }^{*}$ value of each beam, according to its cross-section flange thickness according to the nominal yield stress from EN 10025 [14].

Table 5. Adopted Reference Yield Stress Distributions

\begin{tabular}{|c|c|c|c|}
\hline Steel grade & $\boldsymbol{f}_{\boldsymbol{y}, \text { nom }}$ & $\boldsymbol{f}_{\boldsymbol{y} \boldsymbol{m}} / \boldsymbol{f}_{\boldsymbol{y}, \text { nom }}$ & c.o.v. \\
\hline $\mathrm{S} 235$ & 235 & 1.25 & $5.5 \%$ \\
\hline $\mathrm{S} 355$ & 355 & 1.2 & $5 \%$ \\
\hline $\mathrm{S} 460$ & 460 & 1.15 & $4.5 \%$ \\
\hline
\end{tabular}


The statistical distributions of the geometrical properties were also considered according to the recommendations of the SAFEBRICTILE project Table 6:

Table 6. Adopted Geometrical Distributions

\begin{tabular}{|c|c|c|c|c|}
\hline Dimension & $\boldsymbol{b}$ & $\boldsymbol{h}$ & $\boldsymbol{t}_{\boldsymbol{w}}$ & $\boldsymbol{t}_{\boldsymbol{f}}$ \\
\hline \hline mean/nom & 1 & 1 & 1 & 0.975 \\
\hline c.o.v & $0.9 \%$ & $0.9 \%$ & $2.5 \%$ & $2.5 \%$ \\
\hline
\end{tabular}

The adopted distribution for the modulus of elasticity was based on the recommendations given in DNV[15], and is summarized in Table 7:

Table 7. Statistical Distributions for Modulus of Elasticity DNV [15]

\begin{tabular}{|c|c|}
\hline Mean, $\mathbf{E}_{\mathbf{m}}$ & $\boldsymbol{\sigma}_{\mathbf{E}}$ \\
\hline \hline $1.0 \mathrm{E}_{\text {nom }}$ & $0.05 \mathrm{E}_{\mathrm{m}}$ \\
\hline
\end{tabular}

Concerning the assumptions for the imperfections (material and geometrical), there is not sufficient recent information on initial bow imperfections and residual stresses to allow for the proposal of statistical distributions for these variables. Hence, as for the columns [10], representative values are selected, following the recommendations of EN [2] and [16]. The geometrical imperfections are assumed as an initial imperfection according to the first global buckling mode with an amplitude $e_{0}=L / 1000$. The residual stresses are considered according to Figure 3.2, following ECCS [17]. The value of $f_{y} *$ indicated in Figure 3.2 is considered equal to $235 \mathrm{MPa}$.

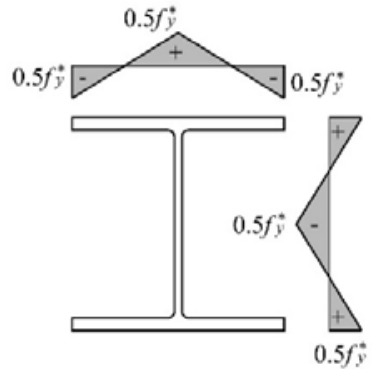

(a) Hot-rolled, $h / b<1.2$

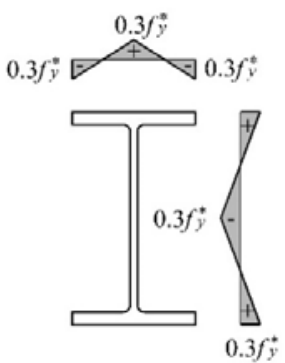

(b) Hot-rolled, $h / b>1.2$

Figure 2. Residual Stresses ("+" Tension and "_"Compression)

It is noted that Taras [3] performed a sensitivity study for the magnitude of the out-of-plane geometrical imperfection, with $e 0$ varying between $\mathrm{L} / 500, \mathrm{~L} / 1000$ and $\mathrm{L} / 2000$. According to his results, the maximum differences found between $\mathrm{L} / 1000$ and the two extremes was about $8 \%$ in the medium slenderness range. Furthermore, a similar study on the magnitude of the residual stresses revealed more than $15 \%$ difference with respect to the consideration of no residual stresses.

Subramanian and White [18], have recently raised some questions concerning the appropriate imperfections to adopt for numerical simulations of the lateral-torsional buckling resistance. Firstly, they have shown that there is no good correlation between experimental tests and numerical simulations when the usual reference values of the imperfections are adopted in the numerical models. Following an "inverse strategy" [18], they back calculated the residual stresses pattern and geometrical imperfection that leads to good agreement with the experimental results reviewed in their paper. Interestingly, they obtained about half the values of the present European recommendations for both imperfections. Furthermore, they have identified that the ECCS recommendations for both geometrical imperfection and residual stresses adopted above are clearly conservative in comparison to the ones adopted in the United States (both in the AISC and the AASHTO recommendations). 
These results show that the adopted representative values for the material and the geometrical imperfections should lead to safe-sided estimates of the lateral-torsional buckling resistance.

\subsection{Numerical Modelling}

In Step 3 of the procedure given in Figure 1, it is required to estimate the relation between the theoretical and experimental estimates of the member resistance. It is considered that advanced finite element simulations can reproduce with sufficient accuracy the real behaviour and therefore those were carried out to obtain "experimental" results. The simulations were performed using finite element software product Abaqus 6.12 [19], using the guidelines established by Marques et al [20] for the modelling of tapered beams subject to LTB with shell elements.

Each beam is modelled with four-node linear shell elements (S4). The analyses were performed using geometrical and material nonlinearities with imperfections, also known as GMNIA. This type of analysis allows capturing the second order effects which are essential for stability problems.

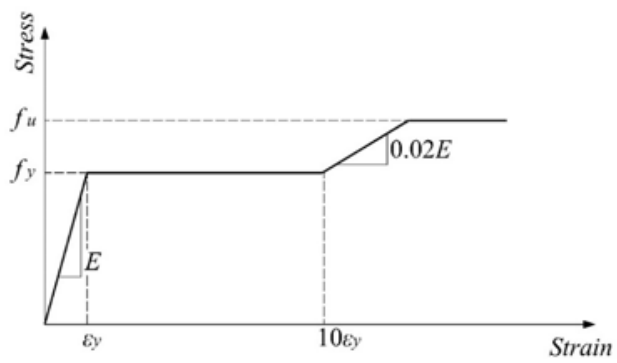

Figure 3. Constitutive Law

Material nonlinearity is incorporated in the model by using elastic-plastic constitutive law with strain-hardening, according to Figure 3, following the recommendations from ECCS [21]. Geometrical imperfections and residual stresses were modelled as described in section 3.3, i.e the initial sweep is assumed according to the first global buckling mode from a linear buckling analysis and the residual stresses are adopted using the ECCS patterns for hot-rolled sections.

The load was applied using a load stepping routine, in which the increment size is chosen in order to meet the accuracy and convergence criteria. The equilibrium equations are solved for each increment using the Newton-Raphson iteration technique.

The adopted mesh comprises 16 sub-divisions in the web and flanges transversely and 100 to 900 divisions along the members' axis depending on the length of the member. Due to the diversity of the cross-sections and the slenderness involved, a maximum relation between the dimensions of the finite elements of about $1 / 4$ was adopted.

The boundary conditions are implemented as end fork conditions in the shell model. The following restraints are imposed: vertical $(\delta \mathrm{y})$ and transverse $(\delta \mathrm{z})$ displacements and rotation about $\mathrm{xx}$ axis $(\phi x)$ are prevented at nodes 1 and 2 . In addition, the longitudinal displacement $(\delta x)$ is prevented at node 1. The flanges and the web at cross-sections A and B (Figure 4) are modelled to remain straight however allowing for warping, i.e., the flanges can move independently from the web. 


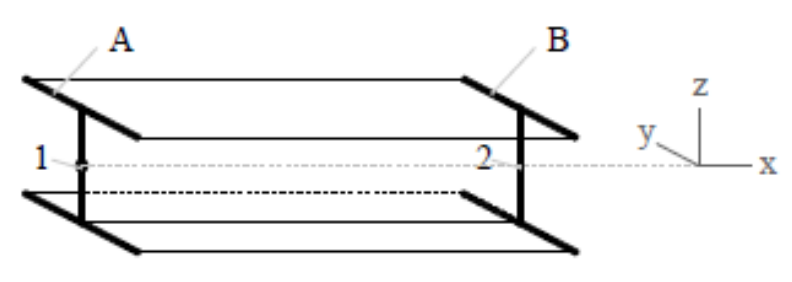

Figure 4. Boundary Conditions

\section{SAFETY ASSESSMENT}

The results from the safety assessment are summarized in this section. Firstly, the scope of the parametric study is defined, followed by the presentation of the methodology to discuss the results and a general overview of the results for all methods. Then, the results for the General Case are presented as reference results for the subsequent comparisons between all the methods. These comparisons are carried out considering only the yield stress $f_{y}$ as a random variable. Finally, the influence of the number of random variables is discussed.

\subsection{Parametric Study: Definition}

Table 8 summarizes the hot-rolled sections selected for the assessment, organized according to the $h / b$ ranges considered by the methods presented in section 2 .

The parametric study consists of 3523 numerical calculation runs. It includes several levels of slenderness and different steel grades (the ones currently included in EUROCODE 3 [1]). The parameters are summarized in Table 9. Due to the diversity of the cross-sections and in order to avoid unrealistic lengths, only beams with ratios $L / h<40$, where $L$ is the beam length and $h$ is the cross-section depth, were considered in the parametric study.

\subsection{Parametric Study: Methodology}

In the following sections, the results for lateral-torsional buckling of beams are detailed. The main topics that are discussed are:

- Comparison of the various design methodologies for the determination of the lateral-torsional buckling resistance of hot-rolled I-beams with fork conditions;

- Influence of the bending moment distribution;

- Assessment of the imperfection factors for the New EC3 method;

- Influence of the number of random variables

Throughout the following paragraphs, charts and tables, the following methodology is adopted:

- The General Case is presented as the reference method for comparative purposes;

- The partial factors for the different subsets are computed considering the Annex $D$ procedure summarized in section 3.2 ;

- A lower tail approximation is applied to all subsets;

- Whenever a subset according to slenderness is analyzed, the following division is adopted:

- Low slenderness - normalized slenderness $\bar{\lambda} \in[0.2 ; 0.8]$;

- Medium slenderness- normalized slenderness $\bar{\lambda} \in(0.8 ; 1.2]$;

- High slenderness - normalized slenderness $\bar{\lambda} \in(1.2 ; 2.1]$; 
- For the first three topics listed above, only the variability of the yield stress is considered, as a relative assessment is sufficient to establish the influence of each parameter;

- In order to establish the influence of additional random variables, the following variables are considered: yield stress, geometrical dimensions of the cross-section and modulus of elasticity.

All detailed results are given in Annex A.

Table 8. Sections of the Parametric Study for Beams

\begin{tabular}{|c|c|c|c|c|c|c|}
\hline \multirow[b]{2}{*}{ Fabrication } & \multicolumn{3}{|c|}{ Limits } & \multicolumn{3}{|c|}{ Sections } \\
\hline & $\begin{array}{c}2] \text { and } \\
\text { EC1993-1-1 } \\
\text { columns } \\
\end{array}$ & $\mathbf{t}_{\mathbf{f}}$ & $\begin{array}{c}\text { EC1993-1-1 } \\
\text { Beams }\end{array}$ & $\mathbf{h} / \mathbf{b}$ & $\begin{array}{c}\mathbf{t}_{\mathbf{f}} \\
{[\mathbf{m m}]}\end{array}$ & Profiles \\
\hline \multirow{30}{*}{ Rolled } & \multirow{21}{*}{$h / b>1.2$} & \multirow{7}{*}{$t_{\mathrm{f}} \leq 40 \mathrm{~mm}$} & \multirow{3}{*}{$\mathbf{h} / \mathbf{b}>\mathbf{2 . 0}$} & 2.22 & 13.5 & IPE400 \\
\hline & & & & 2.50 & 16 & IPE500 \\
\hline & & & & 2.73 & 19 & IPE600 \\
\hline & & & \multirow{4}{*}{$\mathrm{h} / \mathrm{b} \leq \mathbf{2 . 0}$} & 1.82 & 5.7 & IPE100 \\
\hline & & & & 2.00 & 8.5 & IPE200 \\
\hline & & & & 2.00 & 9.8 & IPE240 \\
\hline & & & & 2.00 & 10.7 & IPE300 \\
\hline & & \multirow{14}{*}{$40 \mathrm{~mm}<\mathrm{t}_{\mathrm{f}} \leq 100 \mathrm{~mm}$} & \multirow{6}{*}{$h / b>2.0$} & 2.30 & 68.1 & HL920x725 \\
\hline & & & & 2.56 & 70 & HL1000x748 \\
\hline & & & & 2.31 & 73.9 & HL920x787 \\
\hline & & & & 3.36 & 64 & HE1000x584 \\
\hline & & & & 3.08 & 65 & W920x310x576 \\
\hline & & & & 2.05 & 69.1 & W610x325x551 \\
\hline & & & \multirow{8}{*}{$h / b \leq \mathbf{2 . 0}$} & 1.41 & 40 & HE400M \\
\hline & & & & 1.71 & 40 & HE500M \\
\hline & & & & 1.30 & 19 & HE400A \\
\hline & & & & 1.33 & 24 & HE400B \\
\hline & & & & 2.0 & 30 & HE600B \\
\hline & & & & 2.52 & 41.9 & HL1000x443 \\
\hline & & & & 2.52 & 46 & HL $1000 x 483$ \\
\hline & & & & 2.27 & 51.1 & HL920x537 \\
\hline & \multirow{9}{*}{$\mathrm{h} / \mathrm{b} \leq 1.2$} & \multirow{9}{*}{$t_{\mathrm{f}} \leq 100 \mathrm{~mm}$} & \multirow{9}{*}{-} & 1.00 & 19 & HE300B \\
\hline & & & & 1.00 & 15 & HE200B \\
\hline & & & & 1.00 & 10 & HE100B \\
\hline & & & & 1.13 & 20 & HE100M \\
\hline & & & & 1.10 & 21 & HE300M \\
\hline & & & & 0.95 & 8 & HE120A \\
\hline & & & & 1.09 & 67.6 & HD400x551 \\
\hline & & & & 1.10 & 72.3 & HD400x592 \\
\hline & & & & 1.12 & 77.1 & HD400x634 \\
\hline
\end{tabular}


Table 9. Parametric Study for Beams: Additional Parameters

\begin{tabular}{|c|c|c|c|c|}
\hline Fabrication & $\overline{\bar{\lambda}}_{L T}$ & $\begin{array}{c}\text { Material } \\
\text { standard for } f_{y} \\
\end{array}$ & $\begin{array}{c}\text { Material } \\
\text { imperfections } \\
\end{array}$ & Load \\
\hline Rolled & $\begin{array}{l}0.2 ; 0.4 ; 0.6 ; 0.8 ; \\
1.0 ; 1.1 ; 1.2 ; 1.3 ; \\
1.4 ; 1.5 ; 1.6 ; 1.7 ; \\
1.8 ; 2.0 ; 2.1\end{array}$ & $\begin{array}{c}\text { EN 10025: } \\
\begin{array}{c}\text { S235 } \\
\text { S355 } \\
\text { S460 }\end{array}\end{array}$ & $\begin{array}{r}\mathbf{h} / \mathbf{b} \leq \mathbf{1 . 2}: \\
f_{y, 235} \\
\mathbf{h} / \mathbf{b}>\mathbf{1 . 2}: \\
f_{y, 235}\end{array}$ & $\underline{\underline{s}}$ \\
\hline
\end{tabular}

\subsection{Overview of Results}

Before applying the Annex D procedure for statistical evaluation, it is useful to examine the design model accuracy. In Figure 5 and Figure 6 scatterplots for all the methods are given. In the abscissa, the estimation of the advanced numerical simulations is plotted, while the ordinates correspond to one of the design methods.

In order to give a quantitative measure of the model variations, the statistical parameters for the ratio experimental over theoretical values $\left(\mathrm{r}_{\mathrm{e}} / \mathrm{r}_{\mathrm{t}}\right)$ are given in Table 10, where ratios higher than unity indicate a safe-sided estimation, and on the contrary, ratios lower than 1.0 indicate unsafe results. The General Case and $\mathrm{GC} / \mathrm{f}$ show a high variability of the results, with coefficients of variation of $8.8 \%$ and $7.7 \%$ respectively. The ratios $\mathrm{r}_{\mathrm{e}} / \mathrm{r}_{\mathrm{t}}$ vary from about $10 \%$ unsafe to about $40 \%$ safe.
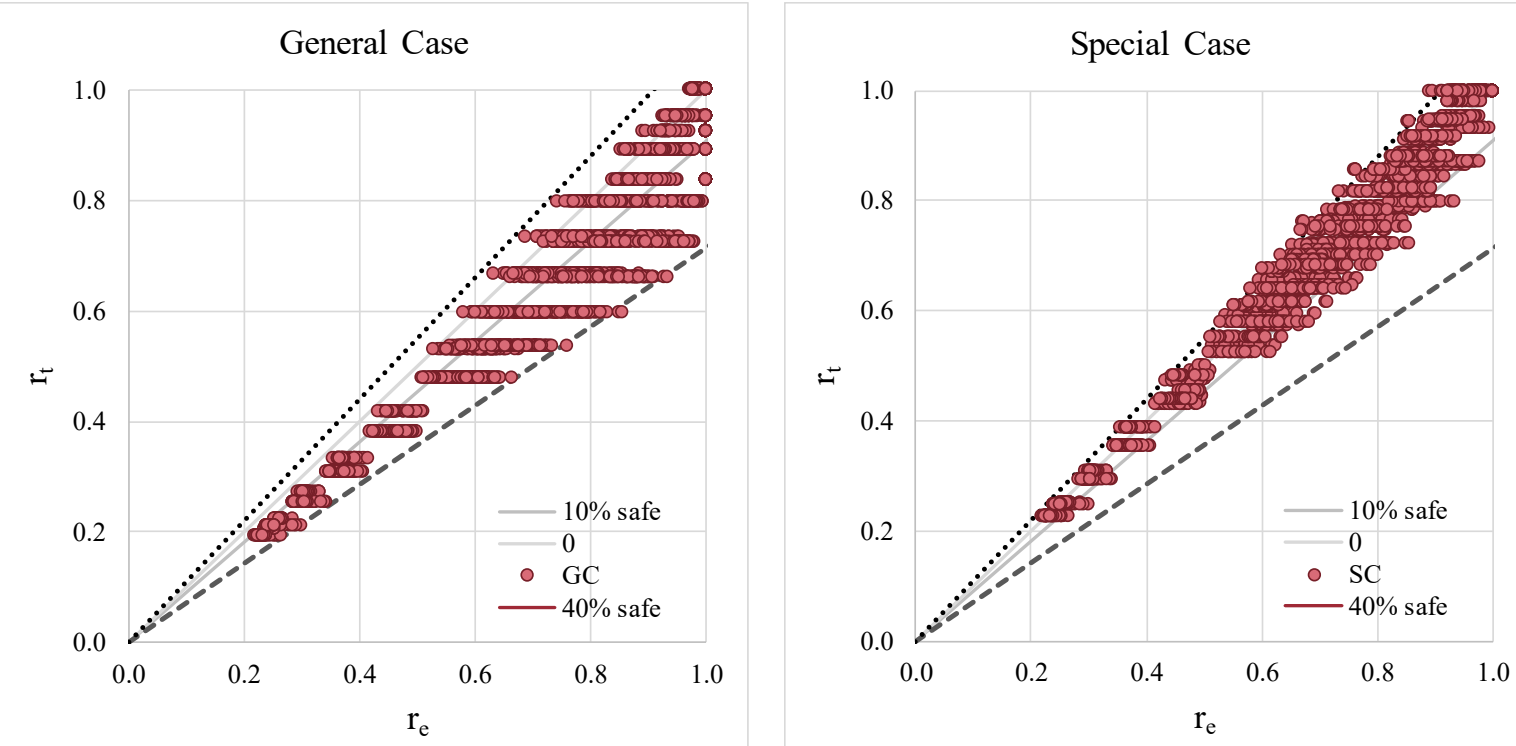

Figure 5. Scatterplots General and Special Case 

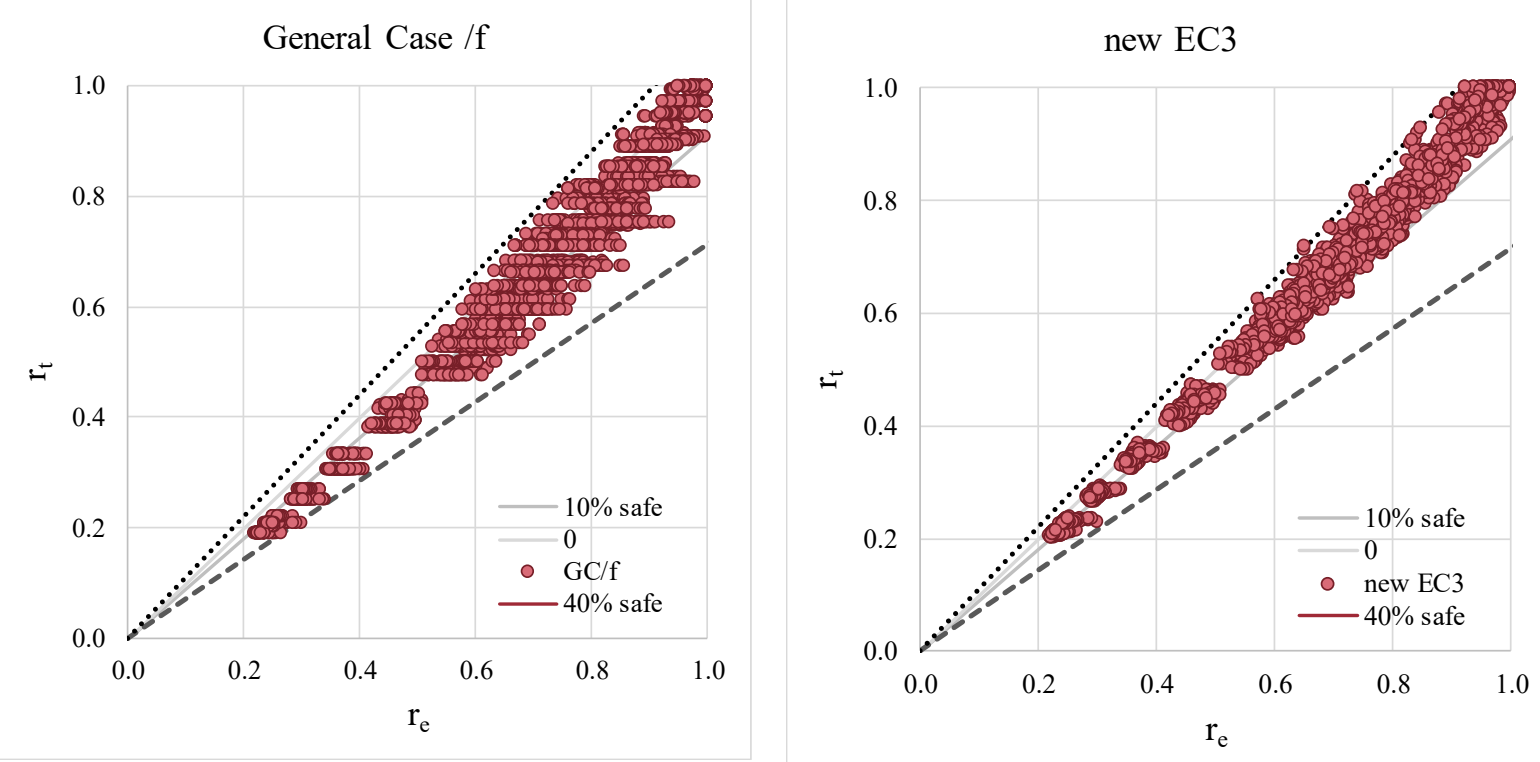

Figure 6. Scatterplots General Case/f and Taras

The other two methods, Special Case and New EC3 have lower coefficients of variation (4.9\% and $4.5 \%$, respectively) but the level of overestimation of the resistance by the Special Case is significantly higher than for the New EC3 method.

Finally, Figure 4.3 illustrates the same results for the AISC [11] code specifications, highlighting a large number of unsafe results $(>55 \%)$ and a high scatter $(9.7 \%)$.

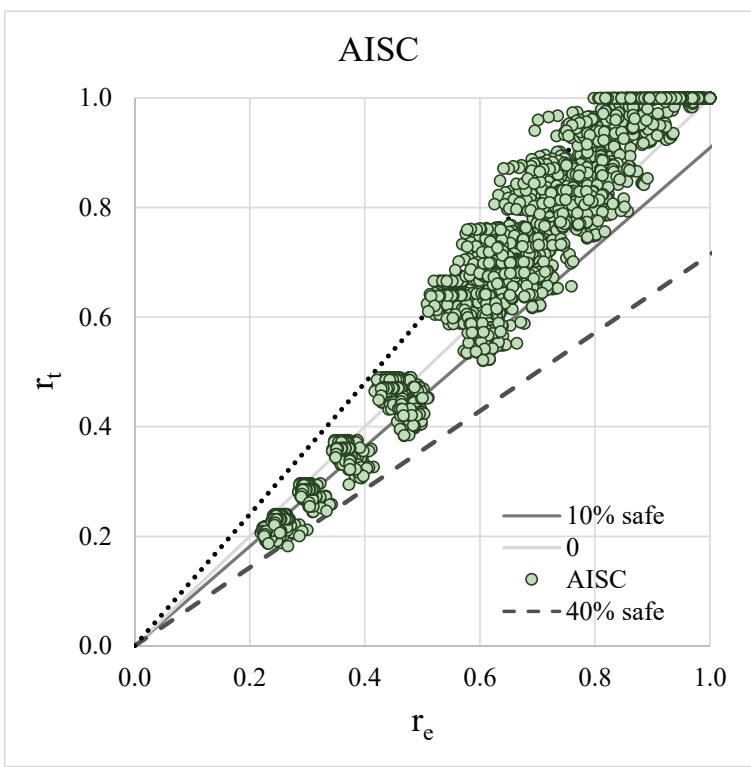

Figure 7. Scatterplots AISC 
Table 10. Statistical Parameters

\begin{tabular}{|c|c|c|c|c|c|}
\hline & nEC3 & GC & SC & GC/f & AISC \\
\hline mean & 1.03 & 1.13 & 1.01 & 1.08 & 0.97 \\
\hline std & 0.05 & 0.10 & 0.05 & 0.08 & 0.09 \\
\hline cov & $4.5 \%$ & $8.8 \%$ & $4.9 \%$ & $7.7 \%$ & $9.7 \%$ \\
\hline min & 0.91 & 0.93 & 0.88 & 0.93 & 0.73 \\
\hline max & 1.30 & 1.44 & 1.21 & 1.43 & 1.46 \\
\hline$<\mathbf{0 . 9 7}$ & 144 & 20 & 625 & 73 & 1641 \\
\hline$<\mathbf{1}$ & 719 & 214 & 1230 & 431 & 1966 \\
\hline
\end{tabular}

These results confirm earlier studies on the lateral torsional buckling of beams [3], [5], [22], whereby a high scatter of the LTB resistances across the slenderness was also observed, from unsafe to very safe for the three first methods.

\subsection{Results and Discussion: General Case}

In this section reference cases considering the General Case are presented. In Figure 8 the $\gamma_{\mathrm{M}}^{*}$ results are divided according to slenderness and steel grade. It is observed that there is not a significant difference between the considered steel grades. The higher results in the low slenderness range occur for all steel grades, reflecting the more decisive role that $f_{\mathrm{y}}$ plays for this slenderness range.

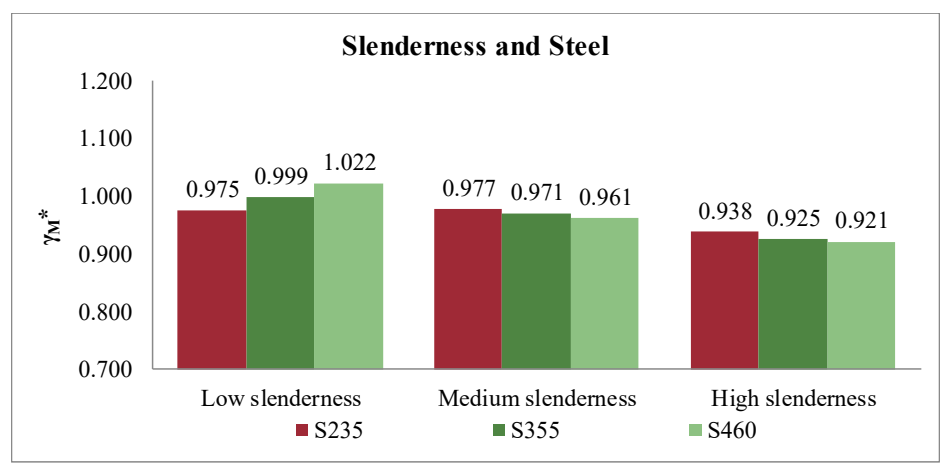

Figure 8. $\gamma_{\mathrm{M}} *$ organized by Slenderness and Steel

Figure 9 and Figure 10 organize the results by buckling curve sub-division. The first compares different steel grades, while the latter compares different slenderness ranges. Figure 9 shows that considering subsets organized by steel grade there is a trend of the $\gamma_{\mathrm{M}}^{*}$ values to increase with the steel grade. This contrasts with the results of Figure 8, highlighting the importance of the consideration of subsets and the sensitivity of results to the choice of subsets [16]. Figure 10 shows that the safety level of the two buckling curves is not homogeneous. 


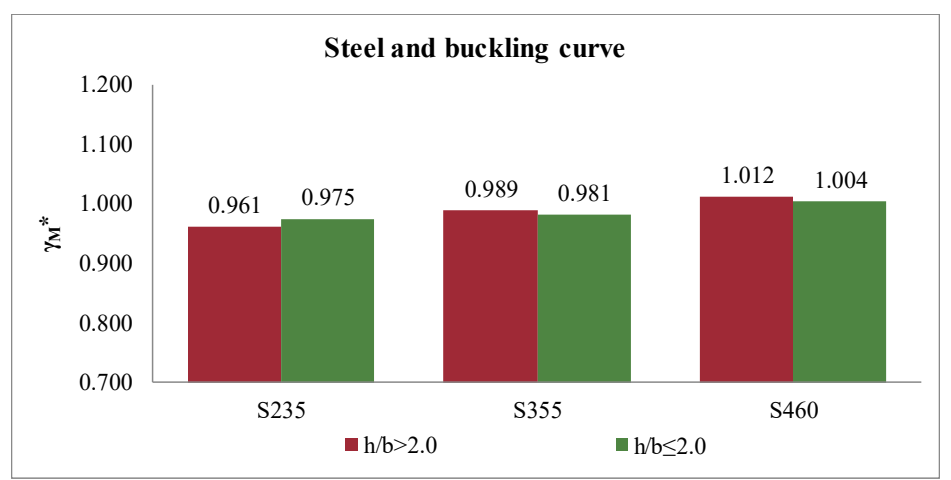

Figure 9. $\gamma_{\mathrm{M}}$ *organized by Buckling Curve and Steel Grade for General Case

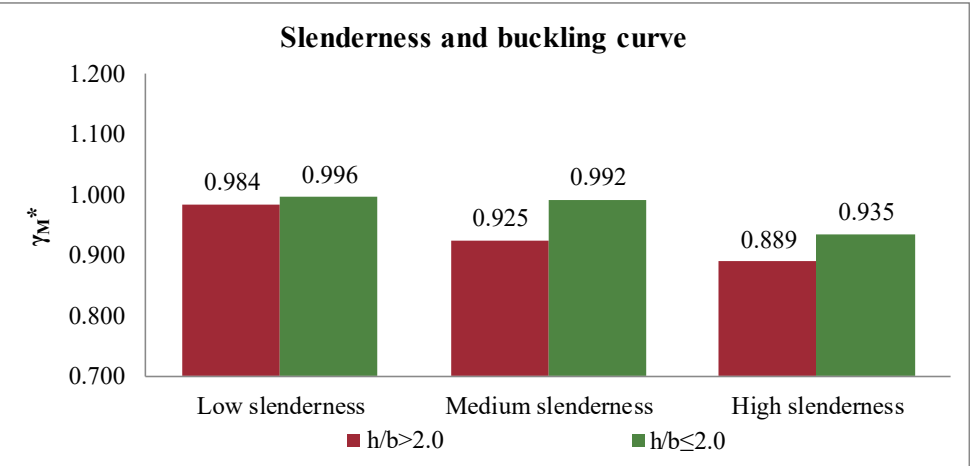

Figure 10. $\gamma_{\mathrm{M}}^{*}$ organized by Buckling Curve and Slenderness for General Case

\subsection{Comparison of the design methods}

\subsubsection{General results}

This section compares the 4 methods. In particular, the influence of the buckling curves and the shape of the bending moment are examined in detail.

Figure 11 compares the General Case, the Special Case, General Case/f and the New EC3 method, according to the slenderness range based on all results available. The Special Case exhibits lower safety, confirming the results of Table 4.3. New EC3 method shows consistent safety across the various slenderness ranges, while the General Case yields significantly higher safety for the medium and high slenderness ranges.

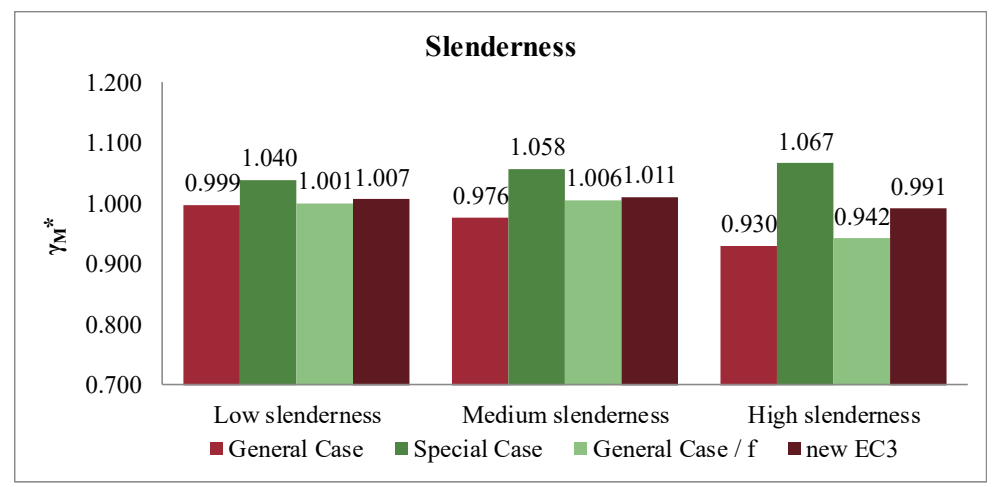

Figure 11. $\gamma_{\mathrm{M}}^{*}$ organized by Slenderness 


\subsubsection{Influence of the buckling curve}

In order to verify the consistency according to the buckling curves, the respective subsets are considered. Figure 12 and Figure 13 compare the several methodologies organized by their respective buckling curve and slenderness divisions (General Case, Special Case and General Case/f are split for $h / b>\leq 2$, while for the New EC3 method the buckling curves are divided for $h / b>\leq 1.2$, in order to match the definition of buckling curves for the columns). This subdivision of the buckling curves presents the advantage of matching the subdivision of column buckling curves. The imperfection factors are adopted as given in Table 2 .

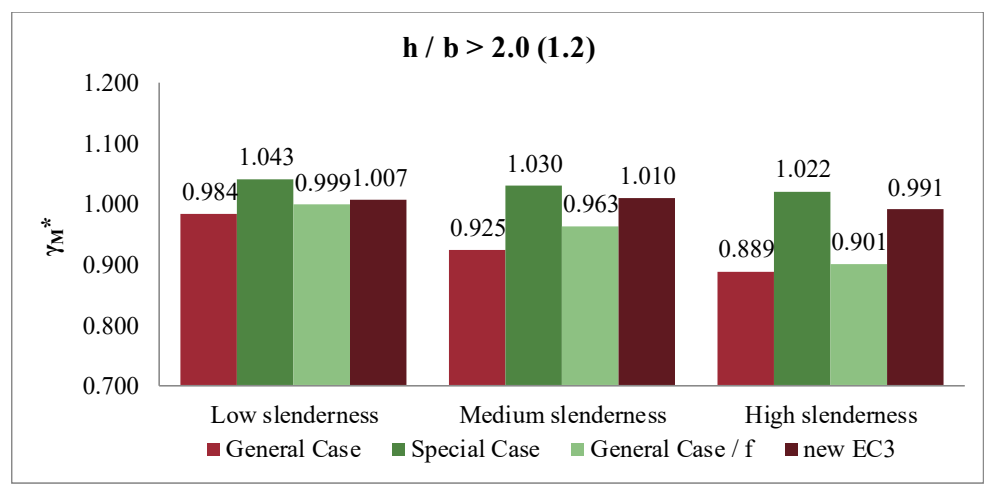

Figure 12. $\gamma_{\mathrm{M}}^{*}$ organized by Buckling Curve and Slenderness

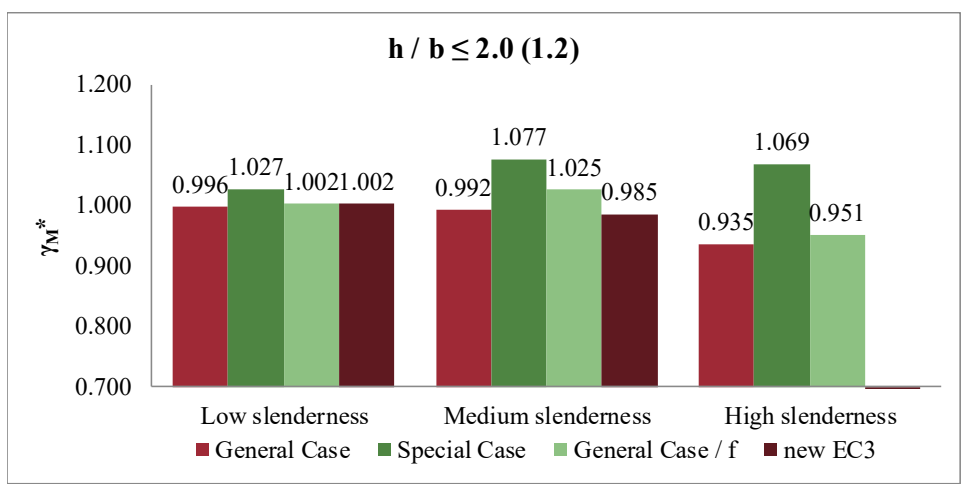

Figure 13. $\gamma \mathrm{M}^{*}$ organized by Buckling Curve and Slenderness

It is seen that for all methods except the New EC3 method, the results for $\mathrm{h} / \mathrm{b} \leq 2.0$ (1.2) are higher in the medium and high slenderness ranges.

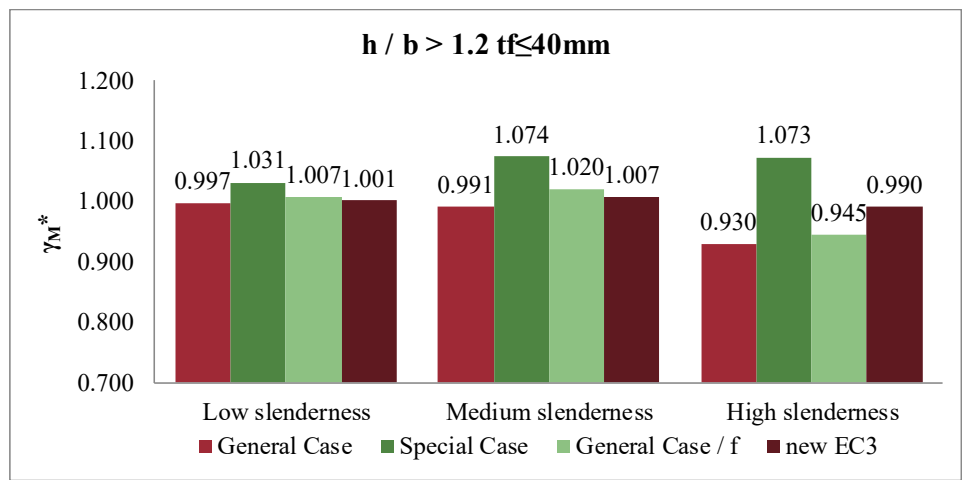

Figure 14. $\gamma \mathrm{M}^{*}$ organized by Buckling Curve Division for Hot-rolled Columns and Slenderness 
Unlike the buckling curve divisions for columns, the imperfection factors for beams are independent of the flange thickness. In order to verify the influence of the flange thickness, further subsets according to the divisions for buckling curves for the columns are considered. Figure 14, Figure 15 and Figure 16 summarize the results according to slenderness for each interval of the column buckling curves. The results for General Case, Special Case and General Case /f given in Figure 14 and Figure 15 are not very different than the ones in Figure 13, the Special Case showing results with higher safety factors with significant differences in the medium and high slenderness. Finally, for $h / b<=1.2$ (Figure 16) all methods show similar results except the General Case in the intermediate slenderness range that is significantly more conservative. It is noted that, in this case, there are no cases in the high slenderness range because they would correspond to unrealistic long beams.

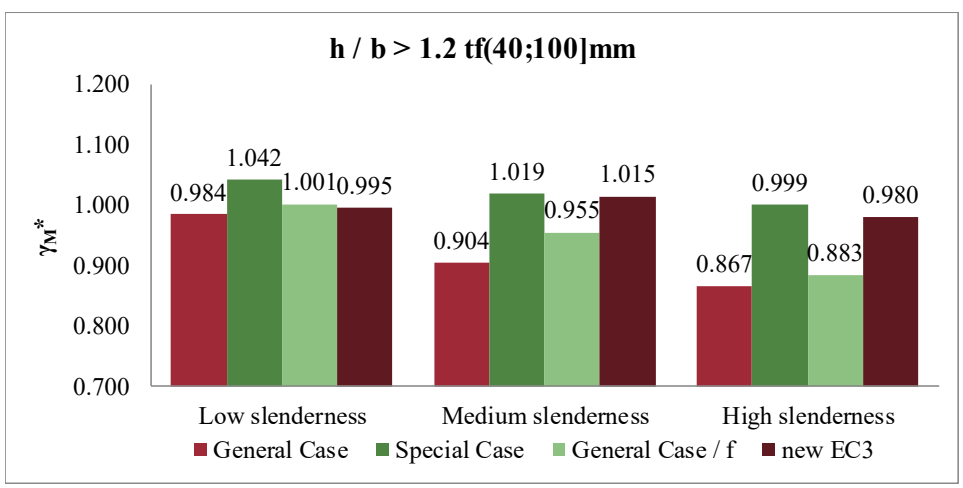

Figure 15. $\gamma_{\mathrm{M}}{ }^{*}$ organized by Buckling Curve Division for Hot-rolled Columns and Slenderness

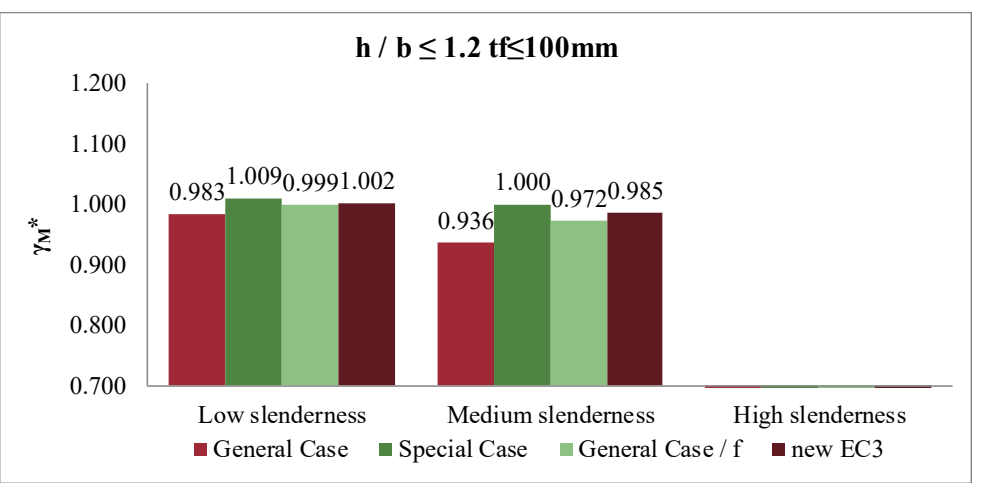

Figure 16. $\gamma_{\mathrm{M}}{ }^{*}$ organized by Buckling Curve Division for Hot-rolled Columns and Slenderness

\subsubsection{Influence of the shape of the bending moment}

The bending moment distribution is an important parameter, which influences the lateral-torsional buckling behaviour of beams. Hence, in this section divisions according to load case and slenderness are presented for the various methods (Figure 17 to Figure 21).

Firstly, it is clearly seen that the General Case is unable to capture the beneficial effect of non-uniform bending moment distributions and thus severely underestimates the LTB resistance, (Figure 17 to Figure 21). As discussed in [5], the GC/f provides a good estimation of the resistance, despite the $f$ factor being based on calibration to numerical results without any mechanical meaning [3]. The New EC3 method provides relatively uniform partial factors for all load cases and across the various slenderness ranges. The Special Case exhibits considerably higher results mainly in the high slenderness range for all load cases. 


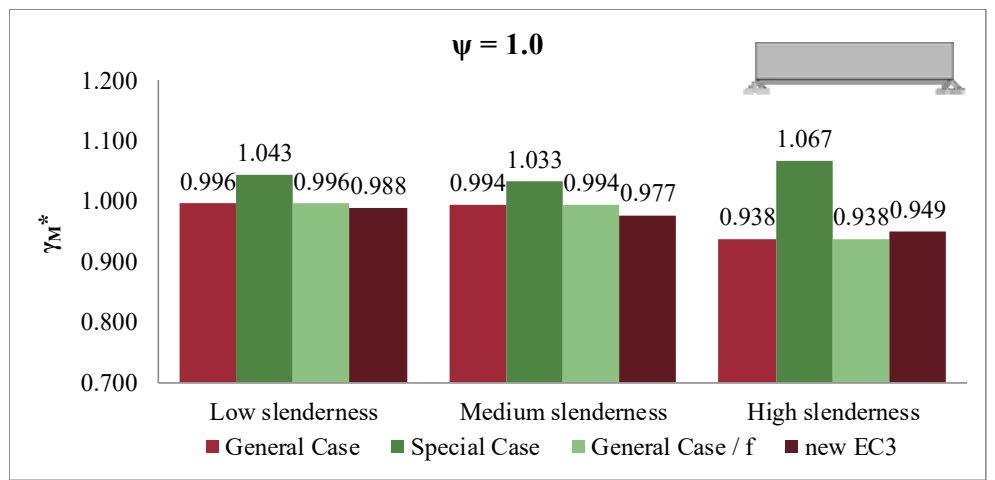

Figure 17. $\gamma \mathrm{M}^{*}$ organized by Bending Moment Distribution - Constant Bending Moment

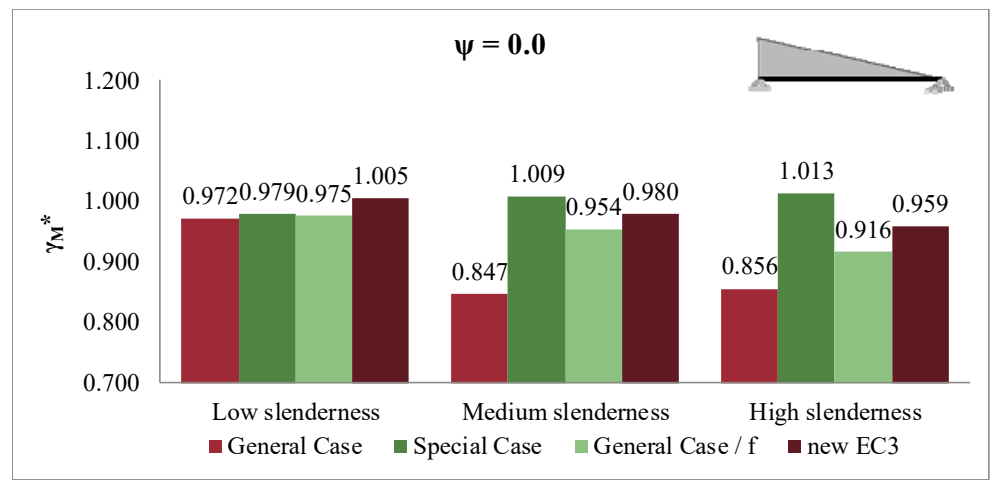

Figure 18. $\gamma_{\mathrm{M}}$ * organized by Bending Moment Distribution - Triangular Bending Moment

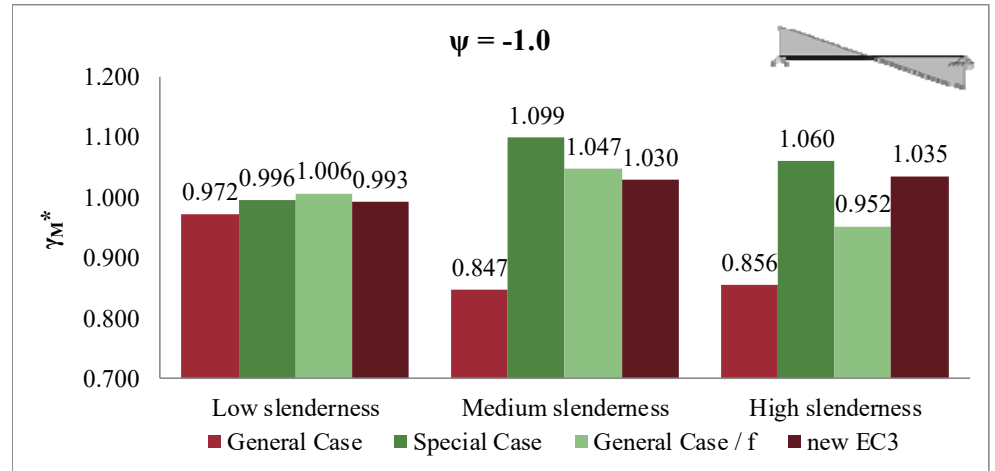

Figure 19. $\gamma_{M}$ *organized by Bending Moment Distribution - bi-triangular Bending Moment

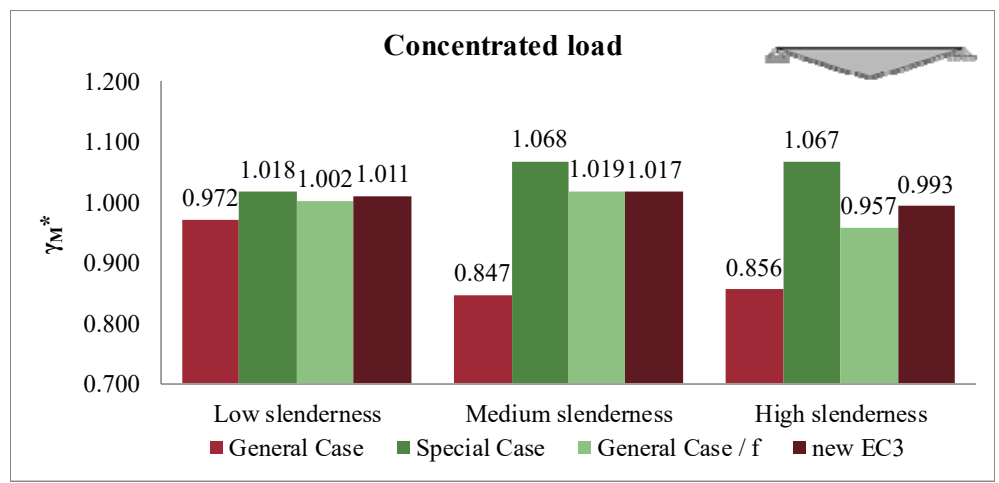

Figure 20. $\gamma_{\mathrm{M}}^{*}$ organized by Bending Moment Distribution - Concentrated Load 


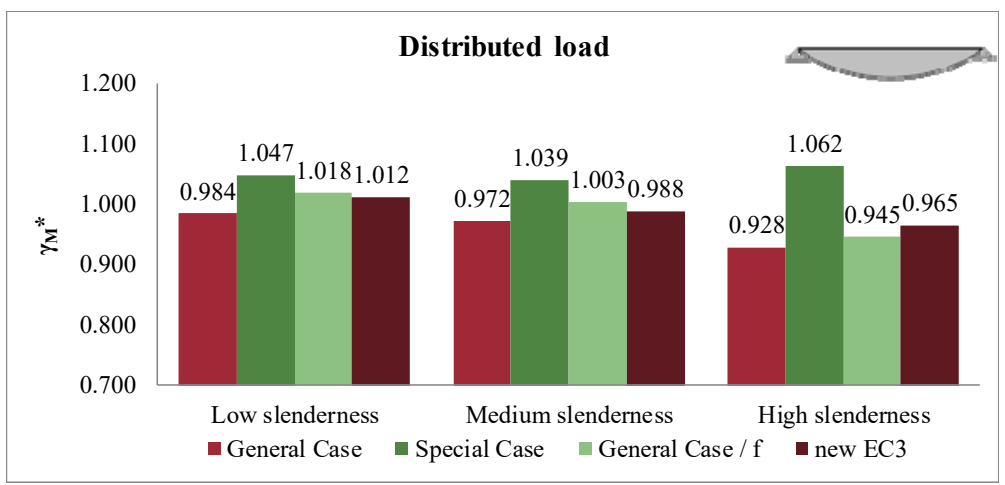

Figure 21. $\gamma_{\mathrm{M}}^{*}$ organized by Bending Moment Distribution - Distributed Load

\subsection{Buckling Curves for the New EC3 Method}

Originally, the buckling curves for the New EC3 method were proposed as shown in Table 11 that differs from Table 2 for the range $\mathrm{h} / \mathrm{b}>1.2,40 \mathrm{~mm}<\mathrm{t}_{\mathrm{f}} \leq 100 \mathrm{~mm}$.

Table 11. Original Imperfection Factors for the New EC3 Method

\begin{tabular}{|c|c|c|c|c|c|c|c|}
\hline \multirow[b]{2}{*}{ Fabrication } & \multicolumn{3}{|c|}{ Limits } & \multicolumn{4}{|c|}{ Source and Method } \\
\hline & \multicolumn{2}{|r|}{ [3] } & EUROCODE 3 & $\begin{array}{c}\text { EUROCODE } 3 \\
\text { GC; GC/f }\end{array}$ & $\begin{array}{c}\text { EUROCODE } 3 \\
\text { SC }\end{array}$ & & nEC3 \\
\hline \multirow{3}{*}{ Rolled } & \multirow{2}{*}{$\hat{n}_{\hat{n}}^{N}$} & $t_{1} \leq 40 \mathrm{~mm}$ & $\begin{array}{l}h / b>2.0 \\
h / b \leq 2.0\end{array}$ & $\begin{array}{c}0.34 \\
0.21\end{array}$ & $\begin{array}{c}0.49 \\
0.34\end{array}$ & 0.12 & $\sqrt{\frac{W_{y, e l}}{W_{z, e l}}} \leq 0.34$ \\
\hline & & $40 \mathrm{~mm}<t_{\mathrm{t}} \leq 100 \mathrm{~mm}$ & $\begin{array}{l}h / b>2.0 \\
h / b \leq 2.0\end{array}$ & $\begin{array}{l}0.34 \\
0.21\end{array}$ & $\begin{array}{l}0.49 \\
0.34\end{array}$ & 0.12 & $\overline{\frac{W_{y, e l}}{W_{z, e l}}} \leq 0.34$ \\
\hline & 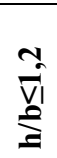 & $t_{t} \leq 100 \mathrm{~mm}$ & $\begin{array}{l}h / b>2.0 \\
h / b \leq 2.0\end{array}$ & $\begin{array}{l}0.34 \\
0.21\end{array}$ & $\begin{array}{l}0.49 \\
0.34\end{array}$ & 0.16 & $\overline{\frac{W_{y, e l}}{W_{z, e l}}} \leq 0.49$ \\
\hline
\end{tabular}

Figure 21 compares the values of $\gamma_{\mathrm{M}}^{*}$ for the thickness range $40 \mathrm{~mm}$ to $100 \mathrm{~mm}$ for all methods using the original imperfections from Table 11 for the New EC3 method. It shows that the New EC3 method presents worse results than the SC for this thickness range. This reflects the fact that the method was calibrated for sections with flange thicknesses lower than $40 \mathrm{~mm}$ [3].

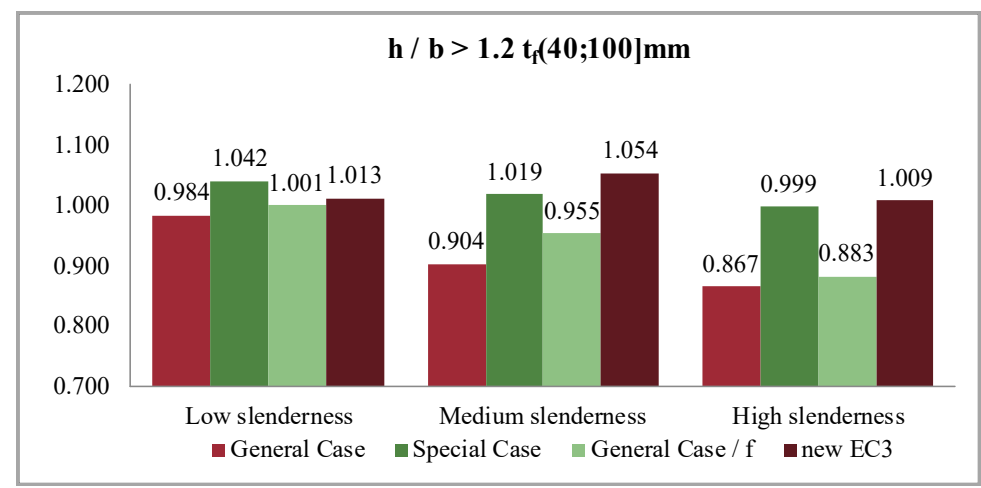

Figure 22. $\gamma_{\mathrm{M}}{ }^{*}$ organized by Buckling Curve Division for Hot-rolled Columns and Slenderness (Old Imperfection Factors) 
Hence, recalibration of the imperfections for the thickness range $40 \mathrm{~mm}$ to $100 \mathrm{~mm}$ led to the imperfection factor of Table 2. The corresponding comparison is illustrated in Figure 22, showing a clear improvement by adopting the same buckling curve as for cross-sections with $\mathrm{h} / \mathrm{b}>1.2$.

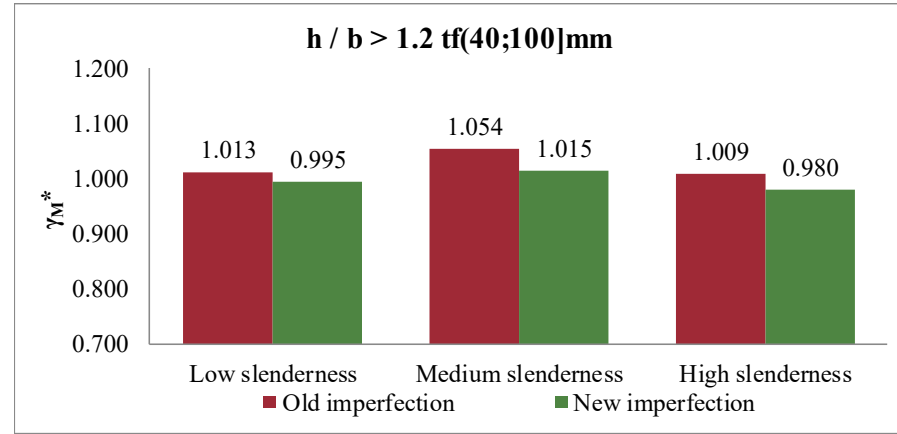

Figure 23. $\gamma_{M}^{*}$ Evaluated Using Old and

Recommended Imperfection Factors for New EC3 Method

\subsection{Influence of the Number of Random Variables}

In all previous comparisons, only the yield stress $f_{y}$ was considered as a random variable. In reality, in the case of lateral-torsional buckling of beams, other basic variables also affect the behavior of a beam, such as the cross-section dimensions and the Young's modulus. It is noted that geometrical and material imperfections such as initial curvature and residual stresses are not considered as basic random variables as they are included implicitly in the design model [8]. Hence, in this section, the following basic variables are considered as random variables: yield stress $-f_{y}$; geometrical dimensions $-b, h, t_{w}, t$; and Young's modulus $-E$. Their statistical parameters were defined in section 0 . In order to highlight their influence, the following cases are considered:

- Annex D (fy) - considers the yield stress as the only basic variable, the other parameters are assumed as deterministic quantities with no variability;

- Annex D (fy+CS) - considers the yield stress and the geometrical dimensions of the cross-section as random variables;

- Annex D (fy+CS+E) - considers the yield stress, the geometrical dimensions of the cross-section and the modulus of elasticity as random variables;

The General Case is presented as the reference case for this assessment. Figure 24 compares the results for the 3 cases defined above, according to slenderness range. Similarly, to the observations in [10], the increased number of random variables leads to higher partial factors. This effect becomes more noticeable with increasing slenderness due to the increased influence of the geometrical properties and the modulus of elasticity. Similar results are obtained for the other methods (see Table A.1). Figure 25 illustrates the corresponding results for the New EC3 method. 


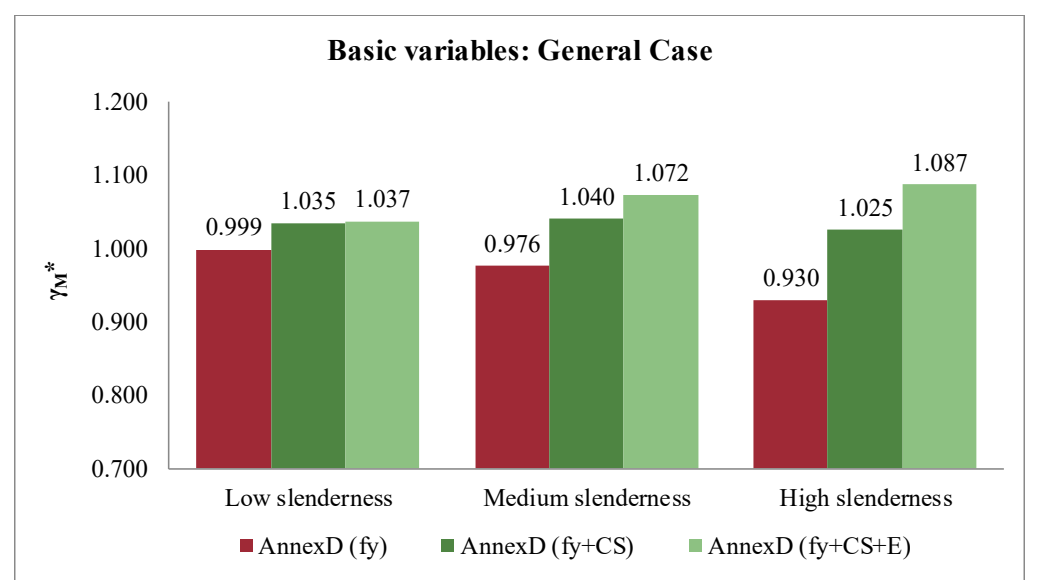

Figure 24. $\gamma_{\mathrm{M}}^{*}$ by Slenderness and Using Different Number of Random Variables: GC

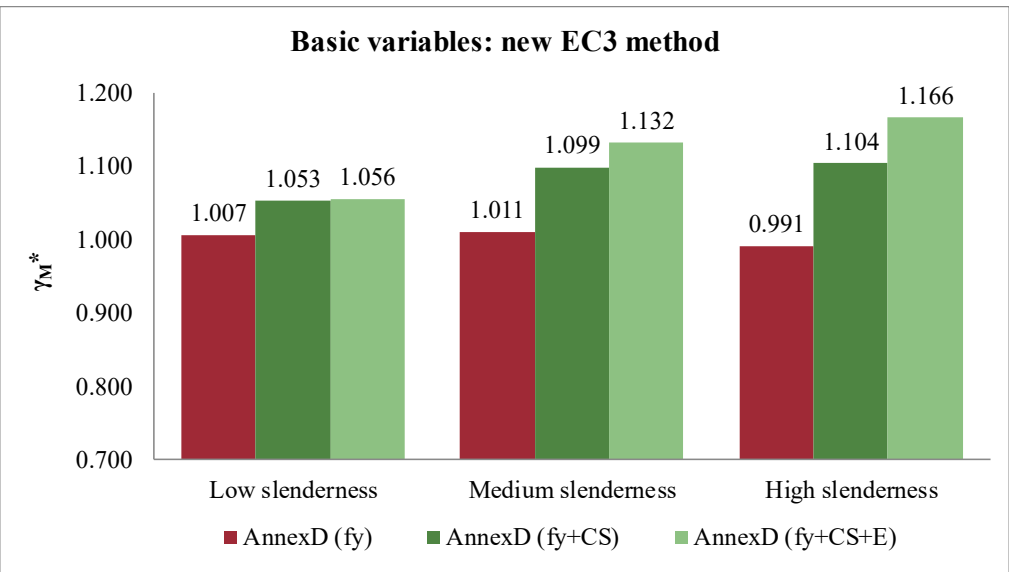

Figure 25. $\gamma_{\mathrm{M}} *$ by Slenderness and Using Different Number of Random Variables: New EC3

\section{ASSESSMENT OF THE VALUE OF THE PARTIAL FACTOR}

Table 12 summarizes the results for $\gamma_{M} *$ for the three different sets of random variables that were considered and the four design methods, using a lower tail approximation due to the systematic deviation from a normal distribution. The conclusion from the previous section is confirmed for all methods - depending on the random variables included in the analysis (just $f y$; $f y$ and cross-section geometry; or $f y$, cross-section geometry and modulus of elasticity E) the partial factor increases its magnitude.

Firstly, except for the Special Case, a good homogeneity of results is observed across the different buckling curves, with maximum variations of 0.05 . However, it is interesting to notice that making the assessment only considering sub-sets according to slenderness for all cases (see also Table A.1) leads to significantly higher values of $\gamma_{\mathrm{M}^{*}}$, highlighting the importance of considering different buckling curves.

Secondly, the Special Case systematically presents higher partial factors ( 0.05 higher on average) for most of the subsets. The General Case presents the lowest partial factors. However, recalling Table 10, it is clearly over conservative, leading in many cases of practical relevance to values of design resistance up to $40 \%$ lower than those obtained from advanced numerical simulations. 
Table 12. Values of $\gamma_{\mathrm{M} 1} *$ Obtained Using Different Combinations of Basic Variables for All Methods

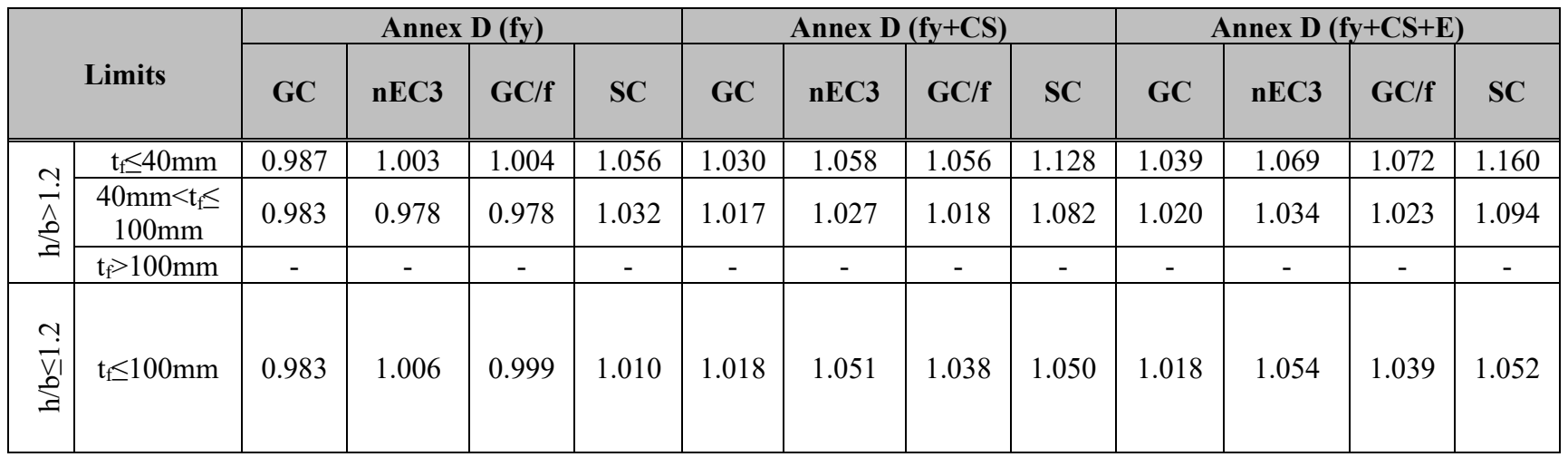

Table 13. Partial Factors for Beams and Columns (fy+CS+E)

\begin{tabular}{|c|c|c|c|c|c|c|c|}
\hline & \multirow{2}{*}{ Limits } & \multirow{2}{*}{ Axis } & \multicolumn{2}{|c|}{$\begin{array}{l}\text { Flexural } \\
\text { Buckling }\end{array}$} & \multicolumn{3}{|c|}{ Lateral-torsional buckling } \\
\hline & & & $\begin{array}{l}\text { S235 } \\
\text { S355 }\end{array}$ & $\mathrm{S} 460$ & EC3 & GC & nEC3 \\
\hline \multirow{3}{*}{ 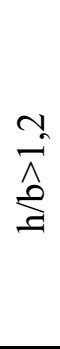 } & $\mathrm{t}_{\mathrm{f}} \leq 40 \mathrm{~mm}$ & $\begin{array}{l}y-y \\
z-z\end{array}$ & $\begin{array}{l}1.079 \\
1.098 \\
\end{array}$ & $\begin{array}{l}1.120 \\
1.118 \\
\end{array}$ & $\begin{array}{l}\mathrm{h} / \mathrm{b}>2.0 \\
\mathrm{~h} / \mathrm{b} \leq 2.0\end{array}$ & 1.039 & 1.069 \\
\hline & $\begin{array}{c}40 \mathrm{~mm}<\mathrm{t}_{\mathrm{f}} \leq 100 \\
\mathrm{~mm}\end{array}$ & $\begin{array}{l}\mathrm{y}-\mathrm{y} \\
\mathrm{z}-\mathrm{z}\end{array}$ & $\begin{array}{l}1.011 \\
1.021 \\
\end{array}$ & $\begin{array}{l}1.063 \\
1.048 \\
\end{array}$ & $\begin{array}{l}\mathrm{h} / \mathrm{b}>2.0 \\
\mathrm{~h} / \mathrm{b} \leq 2.0\end{array}$ & 1.020 & 1.034 \\
\hline & $\mathrm{t}_{\mathrm{f}}>100 \mathrm{~mm}$ & $\begin{array}{l}y-y \\
z-z\end{array}$ & $\begin{array}{l}1.018 \\
1.043 \\
\end{array}$ & $\begin{array}{l}1.067 \\
1.070\end{array}$ & - & - & - \\
\hline \multirow{2}{*}{ 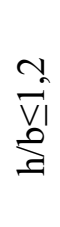 } & $\mathrm{t}_{\mathrm{f}} \leq 100 \mathrm{~mm}$ & $\begin{array}{l}\mathrm{y}-\mathrm{y} \\
\mathrm{z}-\mathrm{z}\end{array}$ & $\begin{array}{l}1.046 \\
1.115 \\
\end{array}$ & $\begin{array}{l}1.094 \\
1.109 \\
\end{array}$ & $\mathrm{~h} / \mathrm{b} \leq 2.0$ & 1.018 & 1.054 \\
\hline & $\mathrm{t}_{\mathrm{f}}>100 \mathrm{~mm}$ & $\begin{array}{l}y-y \\
z-z\end{array}$ & - & - & - & - & - \\
\hline
\end{tabular}

The results from Table 13 support the recent decision by CEN TC250/SC3 to adopt the new Ayrton-Perry-based method [3] as the reference methodology for double symmetric I-and $\mathrm{H}$ cross-sections, while retaining the General Case for the cases that are currently not covered by the New EC3 method (mono-symmetric sections and other cross-sectional shapes).

Table 13 compares the $\gamma_{\mathrm{M}}{ }^{*}$ values for the General Case and the New EC3 method with the results obtained for the flexural buckling resistance of columns considering $f_{y}$, cross-section geometry and $E$ as random variables, using the same statistical characterization of the random variables.

It is observed that the partial factors obtained for LTB of beams are generally lower than those obtained for flexural buckling of columns.

Finally, comparing the Eurocode methods with the AISC methodology, the latter would lead to significantly higher values of the partial factor $\gamma_{M} *$ (See Table 10). 


\section{CONCLUSIONS}

In this paper, the safety assessment of EUROCODE 3 [1] rules for lateral-torsional buckling of prismatic beams with hot-rolled I-shaped cross sections was performed and the partial factor was evaluated considering several subsets, including slenderness range, level of yield stress, EUROCODE 3 [1] buckling curves; flange thickness. The assessment also covered the new EC3 method [3].

Firstly, similar conclusions as stated in [10] for columns are also valid for beams concerning the influence of the adopted minimum yield stress using EN 10025 or Table 3.1 of Eurocode 3 [1].

The results highlight a strong sensitivity of $\gamma_{\mathrm{M} 1}{ }^{*}$ to the subsets that are considered in the calculation. This trend is also confirmed by comparing these results with the corresponding results from [5] and [22]. This difference led to the consideration of a lower tail approximation that significantly improved the homogeneity of results. Globally, the partial factor $\gamma_{M 1}{ }^{*}$ for the New EC3 method is 1.05 , with a c.o.v. of $1.7 \%$.

Regarding the design methods, the conservative nature of the General Case was confirmed, the Special Case systematically led to higher values of $\gamma_{\mathrm{M} 1}{ }^{*}$ for the majority of subsets and the accuracy of the New EC3 method was confirmed. Regarding this method, an adjustment of the imperfection factors is proposed for cross-sections with $\mathrm{h} / \mathrm{b}>1.2$ and flange thickness higher than $40 \mathrm{~mm}$, because this geometric range was not considered in the original derivation of the imperfection factors.

It was shown that the AISC design rules lead to higher resistance predictions, with large scatter. The underlying safety associated with those rules reflects the lower reliability index that is accepted by the American code ( $\beta=2.6$ (approximate value for members) instead of 3.8 as in EN 1993-1-1). Finally, the magnitude of the partial factors was found to be similar or lower than the one obtained for columns and therefore, provided the proposed statistical distributions are respected, it is recommended to keep $\gamma_{\mathrm{M} 1}=1.0$ for beams.

\section{ACKNOWLEDGEMENTS}

The research leading to these results has received funding from:

- the European Community's Research Fund for Coal and Steel (RFCS) under grant agreement SAFEBRICTILE RFS-PR-12103 - SEP no. 601596;

- the Portuguese Foundation for Science and Technology (FCT) under grant agreement SFRH/BD/99702/2014

- partly financed by FEDER funds through the Competitivity Factors Operational Programme - COMPETE and by national funds through FCT - Foundation for Science and Technology within the scope of the project POCI-01-0145-FEDER-007633" 


\section{NOTATIONS}

\section{Latin upper-case letters}

$\mathrm{Cb} \quad$ Lateral-torsional buckling modification factor

$\mathrm{Cw} \quad$ Warping constant

E Modulus of elasticity (210GPa in EN1993 and 200GPa for AISC)

$\mathrm{F}_{\mathrm{y}} \quad$ Specified minimum yield stress

GMNIA Geometrically and materially non-linear imperfection analysis

J Torsional constant

$\mathrm{L}_{\mathrm{b}} \quad$ Length between points that are either braced against lateral displacement of the compression flange or braced against twist of the cross section

$\mathrm{L}_{\mathrm{p}} \quad$ Limiting length

$\mathrm{L}_{\mathrm{r}} \quad$ Limiting length

$\mathrm{M}_{\mathrm{y}, \mathrm{Rk}} \quad$ characteristic resistant bending moment

$\mathrm{M}_{\mathrm{y}, \mathrm{Ed}} \quad$ design value of the bending moment

Mcr elastic buckling critical moment

$\mathrm{Mb}$,Rd design lateral-torsional buckling resistance of the member in bending

$\mathrm{M}_{\mathrm{n}} \quad$ Nominal flexural strength

$\mathrm{M}_{\mathrm{p}} \quad$ Plastic bending momemt

$\mathrm{S}_{\mathrm{x}} \quad$ Elastic section modulus about the $\mathrm{x}$-axis

$V_{X} \quad$ Coefficient of variation

$V_{\delta} \quad$ Estimator for the coefficient of variation of the error term

$\underline{X_{m}} \quad$ Array of mean values of basic variables

$\mathrm{W}_{\mathrm{pl}, \mathrm{y}} \quad$ plastic bending modulus

$\mathrm{W}_{\mathrm{el}, \mathrm{y}} \quad$ elastic bending modulus

Weff,y effective bending modulus

$\mathrm{Z}_{\mathrm{x}} \quad$ Plastic section modulus about the $\mathrm{x}$-axis

\section{Latin lower-case letters}

$b \quad$ Correction factor

c Coefficient ( $=1.0$ for I sections)

$f \quad$ additional factor for bending moment distribution (Special Case)

$h_{0} \quad$ Distance between flange centroids

$g_{r t}(\underline{X})$ Resistance function used as a design model

$k_{d, n} \quad$ Design fractile factor

$N \quad$ Number of experiments or numerical results

$r_{d} \quad$ Design value of the resistance

$r_{e} \quad$ Experimental resistance value

$r_{n} \quad$ Nominal value of the resistance

$r_{t} \quad$ Theoretical resistance determined with $g_{r t}(\underline{X})$

$r_{t s} \quad$ Effective radius of gyration

$r_{y} \quad$ Radius of gyration about y-axis (AISC)

$S \quad$ Estimated value for the standard deviation $\sigma$

$s_{\Delta} \quad$ Estimated value for the standard deviation $\sigma_{\Delta}$ 


\section{Greek upper-case letters}

$\begin{array}{ll}\Delta & \text { Logarithm of the error term } \delta \\ \Delta & \text { Estimated value for } \mathrm{E}(\Delta)\end{array}$

\section{Greek lower-case letters}

$\alpha_{\mathrm{LT}} \quad$ imperfection factor for lateral-torsional buckling

$B \quad$ an additional factor for SC

$\Delta \quad$ Error term

$\delta_{i} \quad$ Observed error term for test specimen i

ๆLT $\quad$ generalized imperfection for lateral-torsional buckling

$\sigma \quad$ Standard deviation

$\sigma_{\Delta}^{2} \quad$ Variance of the term $\Delta$

$\Phi \quad$ additional factors for bending moment distribution

$\chi_{\mathrm{LT}} \quad$ reduction factor for lateral-torsional buckling

\section{REFERENCES}

[1] Eurocode - EN 1993-1-1, Eurocode 3: Design of Steel Structures - Part 1-1: General Rules and Rules for Buildings CEN, Brussels, 2005.

[2] Eurocode - EN 1990, Eurocode - Basis of Structural Design, CEN, Brussels, 2002.

[3] Taras, A., "Contribution to the Development of Consistent Stability Design Rules for Steel Members", PhD Thesis, Technical University of Graz, Graz, Austria, 2010.

[4] Snijder, H.H. and Hoenderkamp, J.C.D., "Buckling Curves for Lateral Torsional Buckling of Unrestrained Beams", Rene Maquoi $65^{\text {th }}$ birthday anniversary, 2007, Liège Belguim.

[5] Rebelo, C., Lopes, N., Simões da Silva, L., Nethercot D. and Vila Real, P.M.M., "Statistical Evaluation of the Lateral-Torsional Buckling Resistance of Steel I-beams, Part 1: Variability of the Eurocode 3 resistance model", Journal of Constructional Steel Research., Elsevier, 2009, Vol. 65, pp. 818-831.

[6] Maquoi, R., Rondal, J., "Mise en Équation des Nouvelles Courbes Européennes de Flambement", Construction Métallique, 1978, No.1, pp. 17-30.

[7] CEN/TC250, Eurocode 3: Design of Steel Structures - Part 1-1: General Rules and Rules for Buildings, CEN/TC 250/SC 3 N 2440 - prEN 1993-1-1 - 2nd draft, 2017.

[8] Tankova, T., Simões da Silva, L., Marques, L., Rebelo, C. and Taras, A., "Towards a Standardized Procedure for the Safety Assessment of Stability Design Rules", Journal of Constructional Steel Research, Elsevier, 2014, Vol. 103, pp. 290-302.

[9] Simões da Silva, L., Marques, L., Tankova, T., Rebelo, C., Kuhlmann, U., Kleiner, A. Spiegler, J., Snijder, H.H., Dekker, R., Dehan, V., Haremza, C., Taras, A., Cajot, L.G., Vassart, O. and Popa, N., "Safebrictile: Standardization of Safety Assessment Procedures across Brittle to Ductile Failure Modes", 2017, RFSR-CT-2013-00023, Final Report.

[10] Simões da Silva, L., Tankova, T., Marques, L. and Rebelo, C., "Safety Assessment of EC3 Stability Design Rules for Flexural Buckling of Columns", Advanced Steel Construction an International Journal, 2016, Vol. 12, No. 3, pp. 328-358.

[11] ANSI/ASCI 360-10, AISC, American Institute of Steel Construction, Specification for Structural Steel Buildings, Chicago, Illinois, USA, 2010.

[12] Kim, Y.D., "Behavior and Design of Metal Building Frames Using General Prismatic and Web-Tapered Steel I-Section Members", Doctoral Dissertation, School of Civil and Environmental Engineering, Georgia Institute of Technology, Atlanta, GA, 2010. 
[13] Subramanian, L.P., Jeong, W.Y., Yellepeddi, R. and White, D.W., “Assessment of I-Section Member LTB Resistances Considering Experimental Tests and Practical Inelastic Buckling Solutions", Structural Engineering, Mechanics and Materials Report No.110, School of Civil and Environmental Engineering, Georgia Institute of Technology, Atlanta, GA, 2016.

[14] CEN, European Committee for Standardization, EN 10025: 2004 - Hot Rolled Products of Structural Steels, 2004.

[15] DNV, Guideline for Offshore Structural Reliability Analysis - Chapter 7, DNV Report No. 95-2018, Det Norske Veritas, Hovik, Norway, 1995.

[16] Taras, A., Dehan, V., Simões da Silva, L., Marques L. and Tankova, T., "Guideline for the Safety Assessment of Design Rules for Steel Structures in Line with EN 1990", Deliverable D1.1, SAFEBRICTILE RFSR-CT-2013-00023, 2017.

[17] ECCS, Ultimate Limit State Calculation of Sway Frames with Rigid Joints, Publication No.33 Brussels, 1984.

[18] Subramanian, L.P. and White, D.W., "Resolving the Disconnect between Lateral Torsional Buckling Experimental Tests and Tests Simulations, and Design Strength Equations", Journal of Constructional Steel Research, Elsevier, 2017, Vol. 128, pp. 321-334.

[19] Abaqus, v.6.12, Dassault Systems/Simulia, Providence, RI, USA, 2012.

[20] Marques, L., Simões da Silva, L., Greiner, R., Rebelo, C. and Taras, A., "Development of a Consistent Design Procedure for Lateral-torsional Buckling of Tapered Beams", In: Journal of Constructional Steel Research, 2013, Vol. 89, pp. 213-235

[21] ECCS, "European Recommendations for Steel Construction", Brussels, 1978.

[22] Simões da Silva, L., Rebelo C., Nethercot D. Marques, L., Simões, R. and Vila Real, P.M.M, "Statistical Evaluation of the Lateral-Torsional Buckling Resistance of Steel I-beams, Part 2: Variability of steel properties", Journal of Constructional Steel Research, Elsevier,.2009, Vol. 65 , No. 4, pp. 832-849. 


\section{Annex A - Results}

Table A.1. All Subsets

\begin{tabular}{|c|c|c|c|c|c|c|c|c|c|c|c|c|c|c|c|c|c|}
\hline \multirow[b]{2}{*}{ Sub-set } & & \multicolumn{4}{|c|}{ General Case } & \multicolumn{4}{|c|}{ Special Case } & \multicolumn{4}{|c|}{ General Case / $\mathrm{f}$} & \multicolumn{4}{|c|}{ Taras } \\
\hline & & $\mathbf{n}$ & $\begin{array}{c}\text { AnnexD } \\
\text { (fy) }\end{array}$ & $\begin{array}{l}\text { AnnexD } \\
(\mathrm{fy}+\mathrm{CS})\end{array}$ & $\begin{array}{c}\text { AnnexD } \\
(\mathrm{fy}+\mathrm{CS}+\mathrm{E})\end{array}$ & $\mathbf{n}$ & $\begin{array}{c}\text { AnnexD } \\
\text { (fy) }\end{array}$ & $\begin{array}{l}\text { AnnexD } \\
(\mathrm{fy}+\mathrm{CS})\end{array}$ & $\begin{array}{c}\text { AnnexD } \\
(\mathrm{fy}+\mathrm{CS}+\mathrm{E})\end{array}$ & $\mathrm{n}$ & $\begin{array}{c}\text { Anne xD } \\
\text { (fy) }\end{array}$ & $\begin{array}{l}\text { AnnexD } \\
(\mathrm{fy}+\mathrm{CS})\end{array}$ & $\begin{array}{c}\text { AnnexD } \\
(\mathrm{fy}+\mathrm{CS}+\mathrm{E})\end{array}$ & $\mathbf{n}$ & $\begin{array}{c}\text { AnnexD } \\
\text { (fy) }\end{array}$ & $\begin{array}{l}\text { AnnexD } \\
(\mathrm{fy}+\mathrm{CS})\end{array}$ & $\begin{array}{c}\text { AnnexD } \\
(\text { fy }+ \text { CS }+ \text { E) }\end{array}$ \\
\hline Low & & 121 & 0.999 & 1.035 & 1.037 & 215 & 1.040 & 1.080 & 1.084 & 130 & 1.001 & 1.040 & 1.045 & 122 & 1.007 & 1.053 & 1.056 \\
\hline Medium & & 216 & 0.976 & 1.040 & 1.072 & 227 & 1.058 & 1.139 & 1.180 & 207 & 1.006 & 1.085 & 1.128 & 204 & 1.011 & 1.099 & 1.132 \\
\hline High & & 103 & 0.930 & 1.025 & 1.087 & 100 & 1.067 & 1.180 & 1.253 & 100 & 0.942 & 1.036 & 1.098 & 101 & 0.991 & 1.104 & 1.166 \\
\hline S235 & & 200 & 0.961 & 0.998 & 1.004 & 158 & 1.044 & 1.112 & 1.141 & 98 & 0.991 & 1.042 & 1.059 & 110 & 1.001 & 1.066 & 1.082 \\
\hline S355 & & 209 & 0.986 & 1.025 & 1.031 & 161 & 1.064 & 1.129 & 1.156 & 301 & 0.984 & 1.025 & 1.032 & 140 & 0.995 & 1.042 & 1.048 \\
\hline 5460 & & 259 & 1.013 & 1.053 & 1.058 & 173 & 1.069 & 1.136 & 1.162 & 310 & 1.005 & 1.048 & 1.054 & 309 & 1.005 & 1.047 & 1.050 \\
\hline \multirow{3}{*}{$\mathbf{S 2 3 5}$} & Low & 33 & 0.975 & 1.010 & 1.012 & 83 & 1.013 & 1.053 & 1.057 & 44 & 0.982 & 1.022 & 1.028 & 57 & 0.991 & 1.039 & 1.044 \\
\hline & Medium & 64 & 0.977 & 1.042 & 1.075 & 57 & 1.057 & 1.135 & 1.174 & 49 & 1.036 & 1.113 & 1.156 & 57 & 1.023 & 1.115 & 1.150 \\
\hline & High & 25 & 0.938 & 1.039 & 1.103 & 21 & 1.069 & 1.190 & 1.264 & 25 & 0.952 & 1.053 & 1.117 & 20 & 0.993 & 1.111 & 1.174 \\
\hline \multirow{3}{*}{ S355 } & Low & 46 & 0.999 & 1.035 & 1.037 & 65 & 1.052 & 1.089 & 1.092 & 47 & 1.004 & 1.044 & 1.048 & 40 & 1.013 & 1.055 & 1.057 \\
\hline & Medium & 71 & 0.971 & 1.035 & 1.068 & 70 & 1.057 & 1.138 & 1.178 & 65 & 1.015 & 1.099 & 1.145 & 69 & 0.985 & 1.074 & 1.106 \\
\hline & High & 37 & 0.925 & 1.024 & 1.087 & 36 & 1.067 & 1.184 & 1.261 & 36 & 0.945 & 1.043 & 1.106 & 33 & 1.012 & 1.121 & 1.183 \\
\hline \multirow{3}{*}{ S460 } & Low & 47 & 1.022 & 1.060 & 1.061 & 67 & 1.067 & 1.110 & 1.113 & 40 & 1.022 & 1.063 & 1.066 & 32 & 1.026 & 1.071 & 1.073 \\
\hline & Medium & 81 & 0.961 & 1.024 & 1.055 & 76 & 1.059 & 1.137 & 1.175 & 81 & 1.013 & 1.095 & 1.138 & 68 & 0.994 & 1.077 & 1.105 \\
\hline & High & 41 & 0.921 & 1.020 & 1.084 & 43 & 1.064 & 1.182 & 1.259 & 44 & 0.942 & 1.040 & 1.102 & 32 & 1.003 & 1.110 & 1.171 \\
\hline \multirow{3}{*}{$\mathbf{h} / \mathbf{b}>\mathbf{2 . 0}$} & 235 & 99 & 0.961 & 0.999 & 1.005 & 83 & 1.023 & 1.091 & 1.118 & 118 & 0.954 & 0.990 & 0.996 & 114 & 1.003 & 1.069 & 1.086 \\
\hline & 355 & 113 & 0.989 & 1.024 & 1.029 & 72 & 1.048 & 1.095 & 1.108 & 119 & 0.983 & 1.020 & 1.024 & 237 & 0.982 & 1.025 & 1.029 \\
\hline & 460 & 115 & 1.012 & 1.049 & 1.054 & 72 & 1.062 & 1.113 & 1.129 & 117 & 1.007 & 1.044 & 1.048 & 234 & 1.004 & 1.050 & 1.054 \\
\hline \multirow{3}{*}{$\mathbf{h} / \mathbf{b} \leq 2.0$} & 235 & 45 & 0.975 & 1.019 & 1.029 & 79 & 1.069 & 1.142 & 1.178 & 48 & 1.016 & 1.082 & 1.109 & 20 & 0.964 & 1.003 & 1.004 \\
\hline & 355 & 112 & 0.981 & 1.020 & 1.024 & 96 & 1.052 & 1.126 & 1.159 & 63 & 1.001 & 1.055 & 1.070 & 20 & 0.994 & 1.034 & 1.036 \\
\hline & 460 & 115 & 1.004 & 1.045 & 1.049 & 88 & 1.066 & 1.142 & 1.175 & 54 & 1.020 & 1.068 & 1.076 & 20 & 1.034 & 1.084 & 1.090 \\
\hline \multirow{3}{*}{$h / b>2.0$} & Low & 106 & 0.984 & 1.016 & 1.017 & 79 & 1.043 & 1.079 & 1.081 & 44 & 0.999 & 1.032 & 1.032 & 91 & 1.007 & 1.053 & 1.057 \\
\hline & Medium & 128 & 0.925 & 0.986 & 1.017 & 114 & 1.030 & 1.115 & 1.159 & 118 & 0.963 & 1.045 & 1.090 & 197 & 1.010 & 1.099 & 1.132 \\
\hline & High & 60 & 0.889 & 0.986 & 1.045 & 72 & 1.022 & 1.143 & 1.216 & 62 & 0.901 & 0.996 & 1.055 & 101 & 0.991 & 1.104 & 1.166 \\
\hline \multirow{3}{*}{$\mathbf{h} / \mathbf{b} \leq \mathbf{2 . 0}$} & Low & 79 & 0.996 & 1.034 & 1.037 & 141 & 1.027 & 1.068 & 1.072 & 97 & 1.002 & 1.044 & 1.050 & 43 & 1.002 & 1.045 & 1.048 \\
\hline & Medium & 97 & 0.992 & 1.061 & 1.095 & 94 & 1.077 & 1.162 & 1.207 & 93 & 1.025 & 1.105 & 1.149 & 20 & 0.985 & 1.058 & 1.075 \\
\hline & High & 36 & 0.935 & 1.038 & 1.103 & 34 & 1.069 & 1.192 & 1.267 & 29 & 0.951 & 1.056 & 1.121 & - & - & - & - \\
\hline \multirow{3}{*}{$\psi=1.0$} & Low & 20 & 0.996 & 1.037 & 1.044 & 60 & 1.043 & 1.082 & 1.084 & 20 & 0.996 & 1.037 & 1.044 & 43 & 0.988 & 1.024 & 1.025 \\
\hline & Medium & 49 & 0.994 & 1.061 & 1.093 & 51 & 1.033 & 1.098 & 1.127 & 49 & 0.994 & 1.061 & 1.093 & 50 & 0.977 & 1.055 & 1.081 \\
\hline & High & 31 & 0.938 & 1.035 & 1.098 & 32 & 1.067 & 1.182 & 1.258 & 31 & 0.938 & 1.035 & 1.098 & 26 & 0.949 & 1.062 & 1.122 \\
\hline \multirow{3}{*}{$\psi=0.0$} & Low & 88 & 0.972 & 1.005 & 1.005 & 20 & 0.979 & 1.014 & 1.015 & 20 & 0.975 & 1.009 & 1.010 & 20 & 1.005 & 1.075 & 1.088 \\
\hline & Medium & 43 & 0.847 & 0.915 & 0.950 & 40 & 1.009 & 1.094 & 1.140 & 44 & 0.954 & 1.034 & 1.079 & 39 & 0.980 & 1.070 & 1.107 \\
\hline & High & 20 & 0.856 & 0.952 & 1.011 & 20 & 1.013 & 1.124 & 1.191 & 20 & 0.916 & 1.005 & 1.062 & 20 & 0.959 & 1.074 & 1.137 \\
\hline & Low & 43 & 0.984 & 1.019 & 1.021 & 38 & 1.047 & 1.083 & 1.086 & 38 & 1.018 & 1.059 & 1.064 & 29 & 1.012 & 1.050 & 1.051 \\
\hline D & Medium & 47 & 0.972 & 1.041 & 1.076 & 53 & 1.039 & 1.111 & 1.144 & 43 & 1.003 & 1.074 & 1.112 & 52 & 0.988 & 1.068 & 1.096 \\
\hline & High & 30 & 0.928 & 1.026 & 1.089 & 29 & 1.062 & 1.178 & 1.251 & 30 & 0.945 & 1.040 & 1.103 & 26 & 0.965 & 1.075 & 1.136 \\
\hline & Low & 47 & 0.962 & 0.995 & 0.995 & 29 & 0.996 & 1.055 & 1.070 & 20 & 1.006 & 1.066 & 1.082 & 20 & 0.993 & 1.059 & 1.070 \\
\hline$\psi=-1.0$ & Medium & 32 & 0.852 & 0.923 & 0.961 & 23 & 1.099 & 1.203 & 1.261 & 29 & 1.047 & 1.139 & 1.191 & 35 & 1.030 & 1.138 & 1.183 \\
\hline & High & 20 & 0.850 & 0.934 & 0.983 & 20 & 1.060 & 1.158 & 1.206 & 20 & 0.952 & 1.046 & 1.098 & 20 & 1.035 & 1.144 & 1.205 \\
\hline & Low & 29 & 0.969 & 1.002 & 1.002 & 31 & 1.018 & 1.059 & 1.063 & 31 & 1.002 & 1.041 & 1.044 & 25 & 1.011 & 1.052 & 1.053 \\
\hline C & Medium & 52 & 0.954 & 1.026 & 1.064 & 53 & 1.068 & 1.150 & 1.193 & 46 & 1.019 & 1.097 & 1.140 & 47 & 1.017 & 1.102 & 1.136 \\
\hline & High & 27 & 0.921 & 1.019 & 1.080 & 23 & 1.067 & 1.183 & 1.253 & 23 & 0.957 & 1.055 & 1.117 & 23 & 0.993 & 1.107 & 1.170 \\
\hline & Low & 70 & 0.997 & 1.034 & 1.037 & 123 & 1.031 & 1.073 & 1.077 & 50 & 1.007 & 1.051 & 1.058 & 82 & 1.001 & 1.046 & 1.049 \\
\hline $\mathrm{h} / \mathrm{b}>1.2$ & Medium & 104 & 0.991 & 1.059 & 1.093 & 112 & 1.074 & 1.159 & 1.204 & 108 & 1.020 & 1.100 & 1.142 & 113 & 1.007 & 1.093 & 1.126 \\
\hline & High & 54 & 0.930 & 1.031 & 1.095 & 49 & 1.073 & 1.193 & 1.268 & 55 & 0.945 & 1.047 & 1.110 & 59 & 0.990 & 1.102 & 1.165 \\
\hline & Low & 83 & 0.984 & 1.016 & 1.017 & 56 & 1.042 & 1.078 & 1.080 & 32 & 1.001 & 1.034 & 1.034 & 39 & 0.995 & 1.036 & 1.038 \\
\hline $\begin{array}{l}h / b>1.2 \\
t>40 m m\end{array}$ & Medium & 89 & 0.904 & 0.970 & 1.000 & 91 & 1.019 & 1.114 & 1.159 & 87 & 0.955 & 1.045 & 1.089 & 66 & 1.015 & 1.113 & 1.147 \\
\hline & High & 31 & 0.867 & 0.977 & 1.033 & 51 & 0.999 & 1.149 & 1.224 & 33 & 0.883 & 0.996 & 1.052 & 41 & 0.980 & 1.108 & 1.166 \\
\hline & Low & 34 & 0.983 & 1.018 & 1.018 & 52 & 1.009 & 1.049 & 1.051 & 20 & 0.999 & 1.038 & 1.039 & 43 & 1.002 & 1.045 & 1.048 \\
\hline $\begin{array}{c}h / b \leq 1.2 \\
t \in 100 \mathrm{~mm}\end{array}$ & Medium & 20 & 0.936 & 0.999 & 1.022 & 20 & 1.000 & 1.065 & 1.084 & 20 & 0.972 & 1.039 & 1.062 & 20 & 0.985 & 1.058 & 1.075 \\
\hline & High & - & & & & - & & & & - & - & - & - & - & - & - & - \\
\hline
\end{tabular}

